\title{
Revisão taxonômica das espécies do gênero Roeboides grupo-affinis (Ostariophysi, Characiformes, Characidae)
}

\author{
Carlos Alberto Santos de Lucena
}

Bolsista de Produtividade CNPq. Laboratório de Ictiologia, Museu de Ciências e Tecnologia, Pontifícia Universidade Católica do Rio Grande do Sul. Av. Ipiranga 6681, 90619-900 Porto Alegre, RS, Brasil. (lucena@pucrs.br)

\begin{abstract}
Taxonomic revision of the Roeboides affinis-group (Ostariophysi, Characiformes, Characidae). A taxonomic study of the species of Roeboides affinis-group is presented. Seven species are recognized: $R$. affinis (Günther, 1868) which inhabits the Amazonian, Orinoco, and Paraná-Paraguay basins, the rivers of Guyana and Suriname, and Tocantins-Araguaia system; R. biserialis Garman, 1890 from river Amazonas basin, R. descalvadensis Fowler, 1932 which occurs in the Amazonas and Paraná-Paraguay basins; $R$. oligistos Lucena, 2000 which inhabits the Amazonian basin; R. numerosus Lucena, 2000 of the river Orinoco basin; R. xenodon (Reinhardt, 1851) from the river São Francisco basin, and R. sazimai n. sp., known only from the Parnaíba and Pindaré-Mearim drainages, northeastern Brazil. Roeboides paranensis Pignalberi, 1975 is considered a synonym of R. descalvadensis; Roeboides prognathus and $R$. thurni Eigenmann, 1912 are synonyms of $R$. affinis. Lectotypes are designaded to $R$. affinis, $R$. biserialis e $R$. francisci Steindachner, 1908. A identification key to the species of Roeboides affinis-group is given.
\end{abstract}

KEYWORDS. Fishes, Neotropical region, taxonomy, nomenclature, South America.

RESUMO. A revisão taxonômica do gênero Roeboides grupo-affinis é apresentada. Sete espécies são reconhecidas: $R$. affinis (Günther, 1868) das drenagens dos rios Amazonas, Orinoco e Paraná-Paraguai, rios da Guiana, Suriname e sistema Tocantins-Araguaia; $R$. biserialis Garman, 1890 da drenagem do rio Amazonas; $R$. descalvadensis Fowler, 1932 das drenagens dos rios Amazonas e Paraná-Paraguai; $R$. oligistos Lucena, 2000 da bacia do rio Amazonas; R. numerosus Lucena, 2000 da bacia do rio Orinoco; R. xenodon (Reinhardt, 1851) da bacia do rio São Francisco e $R$. sazimai sp. nov., conhecida dos rios Parnaíba and Pindaré-Mearim, nordeste do Brasil. Roeboides paranensis Pignalberi, 1975 é considerado sinônimo de $R$. descalvadensis; Roeboides prognathus e $R$. thurni Eigenmann, 1912 sinônimos de $R$. affinis. Lectótipos são designados para $R$. affinis, $R$. biserialis e $R$. francisci Steindachner, 1908. Uma chave de identificação das espécies de Roeboides grupo-affinis é fornecida.

PALAVRAS-CHAVE. Peixes, região Neotropical, taxonomia, nomenclatura, América do Sul.

O gênero Roeboides Günther, 1864 está amplamente distribuído na região Neotropical, desde o sul do México até a bacia do Prata, Argentina. Vinte e uma espécies são reconhecidas para o gênero (LuCENA \& Menezes, 2003; Lucena, 2003), a maioria delas de pequeno porte, poucas podendo a alcançar $19,0 \mathrm{~cm}$ de comprimento padrão como é o caso de Roeboides microlepis (Reinhardt, 1851). A presença característica de dentes situados fora da boca das espécies do gênero, associada ao hábito lepidofágico, em menor ou maior grau, tem levado à estudos de aspectos comportamentais (SAZIMA, 1984; SAZIMA \& MACHADO, 1982), da dieta e do desenvolvimento da estrutura dentária (PETERSON \& Winemiller, 1997; Peterson \& McIntyre, 1998; Hahn et al. 2000; NovaKowsKi et al. 2004).

Estudos recentes realizados com o gênero Roeboides incluem hipóteses de interrelações (LuCENA, 1998; Calcagnotto, et al. 2005) e intrarelações e/ou taxonomia (LuCENA, 2000a, b; 2001; 2003).

LuCEna (1998) propõe a divisão interna de Roeboides em quatro unidades monofiléticas: grupodispar (subclado A em LuCENA, 1998), com uma única espécie que ocorre no sistema dos rios Madeira, Juruá (Brasil) e Napo (Equador), bacia amazônica, caracterizado pela presença de 4 dentes mamiliformes alinhados formando a fileira externa no pré-maxilar e com cerca de 31 a 48 dentes cônicos no maxilar; grupo-guatemalensis (subclado D em Lucena, 1998), com sete espécies de ampla distribuição desde os rios do extremo sul do México (drenagem do Pacífico) e Nicarágua (vertente do Atlântico) até os rios costeiros do noroeste da Guiana, caracterizado pela presença de cúspides nos dentes prémaxilares e pelo reduzido infra-orbital 4 , fazendo parte somente do anel interno da órbita; grupo-microlepis (subclado B em LuCENA, 1998) com quatro espécies que se distribuem nas grandes bacias dos rios Amazonas, Orinoco, Paraguai-Paraná, e no nordeste brasileiro, nos rios Paranaíba e Pindaré-Mearim, caracterizado pela presença de 7 a 10 fileiras de escamas formando uma bainha na base da nadadeira anal, e o grupo-affinis (subclado C em LuCENA, 1998), com representantes nas bacias dos rios Amazonas, Orinoco, Paraguai-Paraná, São Francisco, Paranaíba e Pindaré-Mearim, além das drenagens da Guiana e Suriname. Este último grupo, até o momento, carecendo de estudos de taxonomia; o estudo da filogenia do grupo está em andamento.

As espécies do grupo-affinis podem ser reconhecidas pelo número médio de escamas perfuradas na linha lateral (entre 69 e 83), osso intercalar localizado no limite dos ossos pterótico, exoccipital e pró-ótico, estado reverso a uma condição primitiva (LUCENA, 1998: 37), margem posterior do opérculo com uma extensão pontiaguda para trás (LuCENA, 1998: fig. 7); margem inferior do subopérculo reta (LUCENA, 1998: fig. 7), região ântero-inferior do cleitro com uma pequena projeção dirigida para frente (LuCENA, 1998: fig. 5) e presença de 
faixa transversal de vermiculações nas escamas (LuCENA, 1998: fig. 9).

Nove espécies (Lucena \& Menezes, 2003) compõem atualmente o grupo-affins: $R$. xenodon (Reinhardt, 1851), R. affinis (Günther, 1868), R. biserialis Garman, 1890, R. prognathus (Boulenger, 1895), R. thurni Eigenmann, 1912, $R$. descalvadensis Fowler, 1932, $R$. paranensis Pignalberi, 1975, R. numerosus Lucena, 2000 e R. oligistos Lucena, 2000.

São objetivos do presente trabalho revisar a taxonomia das espécies do grupo-affinis e atualizar suas distribuições geográficas.

\section{MATERIAL E MÉTODOS}

As seguintes instituições são mencionadas neste estudo: ANSP - The Academy of Natural Sciences, Filadelfia; BMHN - The Natural History Museum, Londres; ICN-MHN - Instituto de Ciencias Naturales, Universidad Nacional de Colômbia, Bogotá; INHS Illinois Natural History Survey, Champaign; INPA Instituto de Pesquisas da Amazônia, Manaus; MBUC-VMuseo de Biologia, Universidad Central de Venezuela, Caracas; MCP - Museu de Ciências e Tecnologia da Pontifícia Universidade Católica do Rio Grande do Sul, Porto Alegre; MCZ - Museum of Comparative Zoology, Cambridge; MNHNP - Museo Nacional de Historia Natural del Paraguay, San Lorenzo; MUSM - Museo de Historia Natural, Universidad Nacional mayor de San Marcos, Lima; MZUSP - Museu de Zoologia da Universidade de São Paulo, São Paulo; NRM - Swedish Museum of Natural History, Estocolmo; UF - Florida Museum of Natural History, Gainesville; UMMZ Museum of Zoology, University of Michigan, Ann Arbor; UMSS - Universidad Mayor de San Simon, Cochabamba; UNT - Universidade Federal do Tocantins, Porto Nacional; USNM - National Museum of Natural History, Smithsonian Institution, Washington, D.C.; ROM - Royal Ontario Museum, Toronto; ZMA - Institute for Systematics and Population Biology, antigo Institute of Taxonomic Zoology (Zoologisch Museum), Amsterdam; ZMUC-Zoological Museum, University of Copenhagen, Copenhagen

As medidas e contagens foram feitas segundo FINK \& Weitzman (1974). Os exemplares utilizados para observações das estruturas ósseas foram diafanizados e corados de acordo com técnica de Dingerkus \& UHLER (1977). A contagem das vértebras inclui as quatro do complexo de Weber e a que sustenta o complexo uróforo. A análise dos dados merísticos e morfométricos foi feita com o programa DATAX 4.2 e os testes de significância para os dados merísticos com o SigmaStat para Windows 95,1995 . As medidas obtidas foram analisadas, em alguns casos, pela técnica morfométrica multivariada "Análise das Variáveis Canônicas Livre do Tamanho (AVCLT)" discutida por Bookstein et al. (1985). A AVCLT foi realizada por meio do programa PAST versão 1.08 de HAMmer \& Harper (2003). As variações do número de escamas da linha lateral, número de escamas abaixo e acima da linha lateral, número de escamas ao redor do pedúnculo caudal, e número de rastros branquais do ramo inferior do primeiro arco branquial são mostradas através de gráficos Tukey Box Plots, preparados com o programa SigmaPlot 2.0. para Windows 95 (distribuído por Jandel Scientific). Nas contagens que passavam no teste de normalidade foi aplicado o teste T para verificar o nível de significância. O teste de Mann-Whitney foi aplicado quando os dados merísticos examinados no par de populações falhavam no teste da normalidade. Detalhes sobre estes procedimentos encontram-se em WeITzMan \& Malabarba (1999). Nas representações gráficas dos caracteres merísticos a mediana é representada pela linha vertical espessa no interior da caixa; os percentis de $25 \%$ e $75 \%$ correspondem às laterais da caixa; os percentis de $10 \%$ e $90 \%$ aos traços verticais curtos, e os percentis de $5 \%$ e $95 \%$ aos círculos claros. Os limites das contagens situados além destes círculos estão representados por asteriscos. A média é representada pela linha tracejada.

$\mathrm{Na}$ análise da variação geográfica das populações de Roeboides affinis foram consideradas representantes da região do "alto Amazonas" o conjunto das amostras provenientes dos sistemas dos rios Ucayali, Maranõn, Napo, Putomayo-Içá e Caquetá-Japurá no Peru, Equador e Colômbia. Já a denominação "calha Amazonas", foi considerado o conjunto das amostras coletadas nas proximidades do curso principal dos rios Amazonas/ Solimões e situadas entre as localidades de Tabatinga, Amazonas e a foz do rio Xingu, Pará.

No material examinado, a ordem de apresentação é a seguinte: país; oceano para o qual o sistema fluvial deságua, sempre que auxiliar na sua localização; número de catálogo; entre parênteses, o número de exemplares do lote seguido do comprimento padrão do menor e maior exemplar examinado; localidade; bacia principal quando necessário; cidade, estado ou província, data de coleta e coletores. Em vários lotes não numerados do MZUSP foi adicionado, após ao acronônimo da coleção, a sigla "PB" seguida do número de código, para caracterizar que o material foi coletado por Peter Bayley entre 1977 e 1979. Nas descrições, o valor entre colchetes representa a condição no holótipo ou lectótipo, quando disponível. Roeboides numerosus e $R$. oligistos, por terem sido detalhadamente descritas em LuCENA (2000b), não tem suas descrições repetidas aqui.

As denominações D1 a D5 correspondem aos dentes mamiliformes externos localizados no pré-maxilar - D1 a D3 - e no dentário - D4 e D5 - nas espécies de Roeboides conforme LuCENA (1998: fig 1).

As sinonimias estão restritas às descrições originais, mudanças de gênero e a novos sinônimos. Abreviaturas usadas: $\mathrm{CP}=$ comprimento padrão; $\mathrm{d} \& \mathrm{c}=$ diafanizado e corado; $\mathrm{n}=$ número de exemplares; $\mathrm{m}=$ média.

\section{RESULTADOS}

\section{Chave das espécies de Roeboides grupo-affinis}

1. Duas séries distintas de dentes no dentário; dentes mamiliformes externos anterior e ântero-lateral do dentário, respectivamente, D4 e D5, ausentes; 58 a 64 escamas perfuradas na linha lateral

R. biserialis

1'. Uma série de dentes no dentário; dentes D4 e D5 
sempre presentes; acima de 60 escamas perfuradas na linha lateral.

2. De 12 a 14 rastros branquiais no ramo inferior do primeiro arco branquial .... R. numerosus

2'. De 7 a 11 rastros branquiais no ramo inferior do primeiro arco branquial

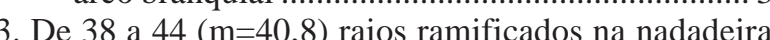
anal; manchas umeral e caudal ausentes

R. oligistos

3'. De 42 a $56(m=49,0)$ raios ramificados na nadadeira anal; manchas umeral e caudal presentes ........... 4

4. De 70 a 88 escamas perfuradas na linha lateral; 13 a 20 escamas abaixo da linha lateral; 15 a 23 escamas acima da linha lateral R. affinis

4'. De 55 a 70 escamas perfuradas na linha lateral; 10 a 16 escamas abaixo da linha lateral; 10 a 17 escamas acima da linha lateral

5. De 7 a 8 rastros branquiais no ramo inferior do primeiro arco branquial R. xenodon

5'. De 9 a 11 rastros branquiais no ramo inferior do primeiro arco branquial

6. Exemplares acima de $60,0 \mathrm{~mm}$ CP comparativamente mais altos $38,1 \%$ a $43,3 \%$ do $\mathrm{CP}(\mathrm{n}=5, \mathrm{~m}=40,2 \%)$ (Fig. 14) e com focinho mais curto $25,5 \%$ a $28,0 \%$ do comprimento da cabeça $(n=5, m=26,6 \%)$; perfil do focinho usualmente convexo....R. descalvadensis

6'. Exemplares acima de $60,0 \mathrm{~mm}$ CP comparativamente mais baixos, $34,8 \%$ a 39,2\% $(n=9, m=37,5 \%)$ (Fig. 14) e com focinho mais longo $27,6 \%$ a $29,4 \%$ do comprimento da cabeça $(n=9, m=28,4 \%)$; perfil do focinho reto R. sazimai, sp. nov.

\section{Roeboides affinis (Günther, 1868)} (Fig. 1)

Anacyrtus affinis GüNTHER (1868: 246) (Localidade-tipo: Huallaga, Peru)

Roeboides bicornis Cope (1870: 564) (Localidade-tipo: Pebas sic Ecuador [Peru, drenagem do rio Solimões, Amazonas Superior]). Anacyrtus prognathus Boulenger (1895: 529) (Localidade-tipo: [sistema do rio] Paraguai). Novo sinônimo.

Roeboides thurni EIGENMANN (1912: 339) (Localidade-tipo: Rockstone, drenagem do Essequibo). Novo sinônimo.

Material examinado. Tipos. PERU, Anacyrtus affinis, Huallaga, Barlett, BMNH 1867.6.13.61 (CP 74,4mm), aqui designado lectótipo; BMNH 1867.6.13.62 (CP 83,6mm), aqui designado paralectótipo. Holótipo: Roeboides bicornis, rio Ambyiacu, J. Hauxwell, ANSP 8151 (aproximadamente CP 51,8mm). COLÔMBIA, Amazonas: boca quebrada Jaguarcaca, Leticia, ICN MHN 2427 (4, CP 84,7 - 98,2mm); Leticia, 4'8'5"S, 69 56'37'W, ICN MHN 5173 (CP 62,2mm); laguna Yahuarcaca, Leticia, ICN MHN 4434 (1, CP 84,8mm); Caquetá: rio Peneya, ICN MHN 3509 (9, CP 46,4 - 72,5mm ); Meta: rio Trampotin, bacia do rio Manacacías, Puerto Gaitán, ICN MHN 668 (2, CP 39,4 - 40,8mm); laguna de Menegua, Puerto Lopez, ICN MHN 1314 (4, CP 33,7 - 77,8mm); Vichada: rio Bita, Puerto Carreño, ICN MHN 3868 (3, CP 32,1- 43,3mm); rio Meta, UMMZ 216760 (5, CP 61,9 - 71,9mm). VENEZUELA, Amazonas: rio Mavaca, $02^{\circ} 11^{\prime} \mathrm{N}, 65^{\circ} 06^{\prime} \mathrm{W}$, INHS 29183 (2, CP 52,4 - 67,8mm); Anzoátegui: rio Catis [Caris?], em Hato El Momón sudeste de El Tigre, INHS 61939 (CP 31,0mm); Apure: afluente do rio Setento, bacia do rio Apure, 07²5'N, 69²0'W, INHS 29811 (CP 53,0mm); riacho na estrada San Fernando de Apure-Arichuma, aprox. $16 \mathrm{Km}$ a sudoeste de San Fernando de Apure, MZUSP 87997 (CP 59,0mm); rio Apurito, afluente do rio Arauca, estrada de ferro que cruza a estrada San Fernando a Cunaviche, $70^{\circ} 33^{\prime} \mathrm{N}$, $67^{\circ} 38^{\prime} \mathrm{W}$, USNM 359770 (5, CP 36,7 - 45,4mm CP); Barinas: afluente do rio Masparro, bacia do rio Apure, INHS 29982 (5, CP 43,8 - 64,8mm); Cojedes: rio Camoruco, bacia do rio Portuguesa, 09 20'03”N, 6842'76”W, IHNS 29030 (2, CP 57,8 - 58,1mm); Guarico: rio San Bartolo, em Aguas Muertas, 08 04'14'N, 664' $50^{\circ}$ 'W, INHS 34480 (7, CP 49,8 - 63,6mm); laguna Larga II, $07^{\circ} 38^{\prime} 55^{\prime \prime} \mathrm{N}, 66^{\circ} 13^{\prime} 40^{\prime \prime} \mathrm{W}$, INHS 35719 (3, CP 47,7 - 49,6mm) rio San Bartolo, na fazenda Bartolena, INHS 61922 (3, CP 44,0 - 57,1mm); rio Apure, MCP 26506 (CP 53,7mm ); ponte sobre o rio Caracol, Fundo Masaguaral, MZUSP 27943 (4, CP 39,9 51,0mm); idem anterior, MZUSP 27942 (2, CP 39,8 - 40,0mm); riacho Falcon, rio Portuguesa, $08^{\circ} 14^{\prime} \mathrm{N}, 67^{\circ} 35^{\prime} \mathrm{W}$, USNM 359593 (4, CP 42,8 - 51,0mm); Delta Amacuro: rio Guarguapo, MCP 26505 (2, CP 61,7 - 65,1 mm); afluente do rio Orinoco, boca do rio Anabata, $08^{\circ} 37^{\prime} \mathrm{N}, 61^{\circ} 48^{\prime} \mathrm{W}$, UMMZ 211295 (CP 63,3mm); rio Orinoco, lagoa no riacho Araguaito próximo ao Km 130, USNM 233178 (18, CP 33,6 - 50,2mm); Monagas: rio Tigre, INHS 31492 (CP 39,2mm); lagoa Los Guateques, Barrancas, MHNG 2189.41 (CP 56,0mm); Portuguesa: rio Igues, Purto Papelon, bacia do rio Apure, INHS 29942 (5, CP 35,8 - 75,1mm); rio Maraca, drenagem do rio Apure, $09^{\circ} 0$ ' $\mathrm{N}, 69^{\circ} 30^{\prime} \mathrm{W}, \mathrm{MCZ}$ 59364 (9, 40,0 - 84,5mm). GUIANA, ROM 64132 (CP 81,2mm); ROM 64135 (4, CP 33,3 - 50,8mm); ROM 64136 (18, CP 18,0 - 89,4mm); rio Puara, Rupununi, bacia do rio Branco, USNM 224808 (3, CP 45,0 - 47,2mm). SURINAME, Brokopondo: rio Marowijne, $63 \mathrm{Km}$ ao sul de Afobaka, MCP 19064 (2, CP $74,8 \mathrm{~mm}, 1 \mathrm{CP} 64,1 \mathrm{~mm} \mathrm{~d} \& \mathrm{c}$ ); rio Suriname, MHNG 2189.40 (CP 78,7mm); rio Marowijne, $63 \mathrm{Km}$ ao sul de Afobaka, MZUSP 10670 (5, CP 65,1 - 88,9mm); riacho Marowijne (=Gran Creeck), [drenagem do rio Suriname] $55 \mathrm{Km}$ ao sul da cidade de Afobaka, ZMA 106.365 (CP 61,7mm); idem anterior, $63 \mathrm{Km}$ da cidade de
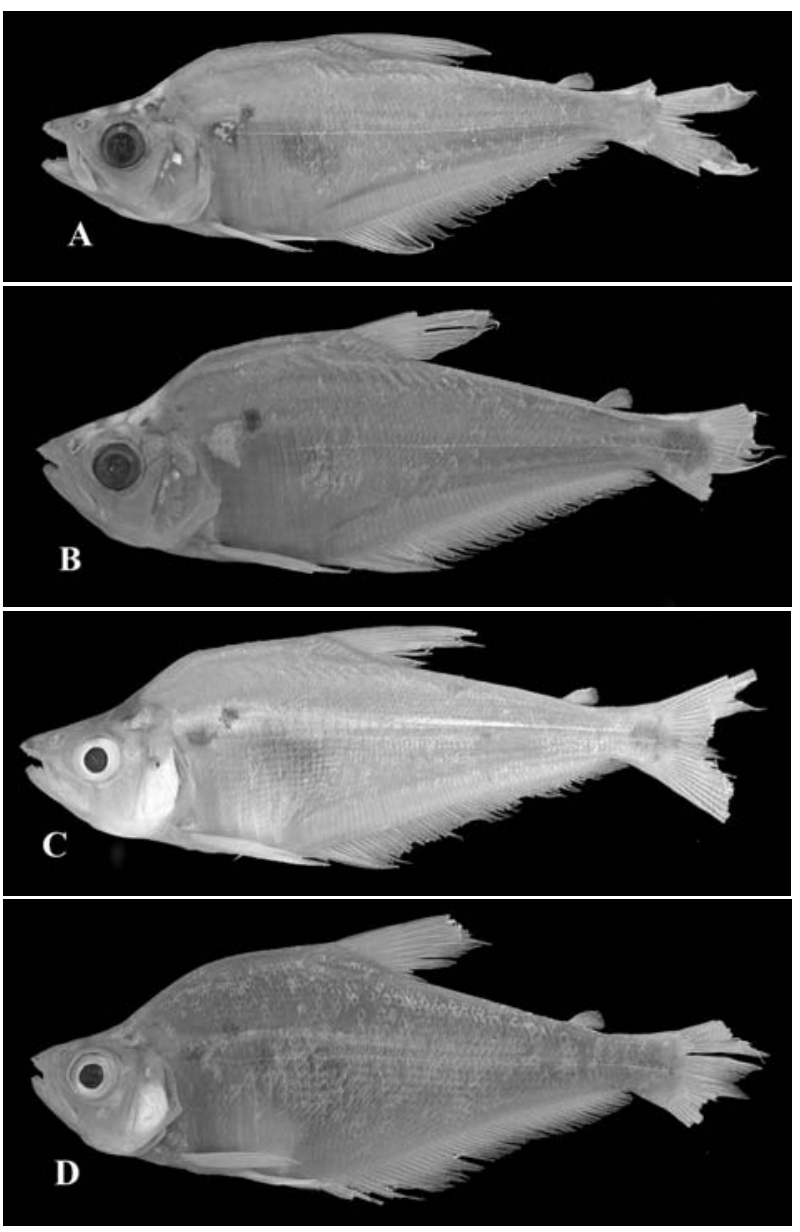

Fig. 1. Roeboides affinis (Günther, 1868), A, MUSM 338, CP 64,1 $\mathrm{mm}$, rio Ucayali, Pucallpa; B, MUSM 1674, CP CP66,1 mm, rio Tamaya, Pucallpa; C, MZUSP 34705, CP 68,2 mm, Calama, rio Madeira; D, MZUSP 34705, CP 65,7mm, Calama, rio Madeira. 
Afobaka, ZMA 106.366 (10, CP 62,2 - 85,4mm); Nickerie: riacho na margem esquerda do rio Nickerie $12 \mathrm{Km}$ a sudeste da corredeira Stondansie, MZUSP 10671 (2, CP 56,2 - 74,8mm); riacho Matappi, $05^{\circ} 01^{\prime} \mathrm{N}, 057^{\circ} 17,5^{\prime} \mathrm{W}$, drenagem do rio Corantijn, USNM 225342 (2, CP 75,2 - 79,8mm); riacho na margem esquerda do rio Nickerie $12 \mathrm{Km}$ a sudeste da corredeira Stondansie, ZMA 106.367(5, CP 54,2 - 75,6mm). EQUADOR, Napo: rio Panayacu, $00^{\circ} 25^{\prime} \mathrm{S}, 7^{\circ} 07^{\prime} \mathrm{W}$, ANSP 131323 (3, CP $55,1-90,5 \mathrm{~mm}$ ); boca do rio Shushufundi, $00^{\circ} 18^{\prime} \mathrm{S}, 76^{\circ} 21^{\prime} \mathrm{W}$, ANSP 131335 (15, CP 43,7 - 64,1mm); Pastaza: rio Curaray, Jesus Pitishca, $01^{\circ} 24^{\prime} \mathrm{S}, 76^{\circ} 54^{\prime} \mathrm{W}$, ANSP 131324 (1, CP 66,9mm). PERU, Loreto: rio Napo, logo acima da boca do rio Mazan, 03⒉'10"S, 7306'24"W, ANSP 178153 (23, CP 24,9 - 89,3mm); rio Amazonas, sul de Iquitos, Maynas, ANSP 178292 (14, CP $49,5-88,2 \mathrm{~mm}$ ); rio Amazonas, próximo à desembocadura do rio Yanuyacu, Maynas, 04 ${ }^{\circ} 14^{\prime} 01^{\prime \prime} S, 73^{\circ} 19^{\prime} 14$ 'W, ANSP 178418 (5, CP 63,6 - 89,3mm); boca do rio Mazan, próximo a Mazan, drenagem do rio Napo, INHS 36608 (7, CP 30, $6-73,5 \mathrm{~mm}$ ); Mayuruna Cocha, drenagem do rio Orosa, $03^{\circ} 35^{\prime} 25^{\prime \prime} \mathrm{S}$, $72^{\circ} 13^{\prime} 05^{\prime}$ "W, INHS 39275 (10, CP 35,9-61,1mm); rio Yanashi, $03^{\circ} 34^{\prime} 06^{\prime}$ "S, 72¹4'58”W, INHS 39333 (CP 51,8mm); rio Itaya, cerca de $5 \mathrm{Km}$ acima de Iquitos, $03^{\circ} 47^{\prime} 71^{\prime \prime} \mathrm{S}, 73^{\circ} 17^{\prime} 29^{\prime \prime} \mathrm{W}$, INHS

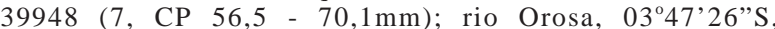
$73^{\circ} 14^{\prime} 59^{\prime}$ 'W, INHS 40146 (2, CP 42,1 - 51,5mm); riacho Manzana, drenagem do rio Itaya, $03^{\circ} 47^{\prime} 48^{\prime \prime} \mathrm{S}, 73^{\circ} 14^{\prime} 90^{\prime \prime} \mathrm{W}$, INHS 40205 (CP 44,8mm); riacho acima da boca do rio Zapatilla, próximo a cidade de Yanashi, $03^{\circ} 47^{\prime} 26^{\prime \prime}$ 'S, $73^{\circ} 14^{\prime} 50$ "W, INHS 40243 (6, CP 56,7 - 75,8mm); rio Napo, $03^{\circ} 28^{\prime} \mathrm{S}, 7^{\circ} 05^{\prime} \mathrm{W}$, INHS 53822 (3, CP 24,7 - 39,6mm); riacho Moema, afluente do rio Itaya, a sudeste de Iquitos, $03^{\circ} 43^{\prime} 20^{\prime \prime} \mathrm{S}, 7^{\circ} 14^{\prime} 17^{\prime \prime} \mathrm{W}$, INHS 53861 (2, CP 45,2 - 52,0mm); rio Yavari, Petropolis, MUSM 121 (5, CP 65,6 - 83,3mm); rio Napo, lagoa Cayapoza, NRM 23745 (5, CP 30,3 - 40,8mm); Madre de Dios: rio Manu, próximo a

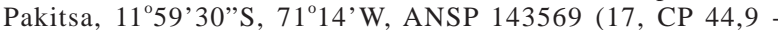
$57,1 \mathrm{~mm}$ ); boca do rio Pinquen, próximo a boca do rio Manu, $12^{\circ} 10^{\prime} \mathrm{S}, 71^{\circ} 01^{\prime} \mathrm{W}$, ANSP 143570 (4, CP 55,5 -84,7mm); lago Tupuhumaro, noroeste de Puerto Maldonado, acima do rio de Las Piedras, $12^{\circ} 33^{\prime} \mathrm{S}, 69^{\circ} 13^{\prime} \mathrm{W}$, ANSP 143571 (CP 45,7mm); rio Manu, próximo a Pakitsa, $11^{\circ} 59^{\prime} 30^{\prime \prime}$ S, $01^{\circ} 14^{\prime} \mathrm{W}$, ANSP 143574 (2, CP 50,8 - 51,6mm); rio Manu, $12^{\circ} 11^{\prime} \mathrm{S}, 70^{\circ} 58^{\prime} \mathrm{W}$, ANSP 143575 (1, CP 49,3mm); rio Manu, próximo a Pakitsa, $11^{\circ} 59^{\prime} 30^{\prime \prime} \mathrm{S}, 71^{\circ} 14^{\prime} \mathrm{W}$, ANSP 151496 (1, CP 52,3mm); rio Tahuamanu, próximo a San Lorenzo, $11^{\circ} 27^{\prime} 46^{\prime \prime}$ 'S $71^{\circ} 14^{\prime} \mathrm{W}$, ANSP 180869 (3, CP 41,1-61,6mm); rio la Torre, Tambopata, MUSM 8703 (10, CP 60,6 - 94,7mm); boca de la quebrada Juliaca, Tambopata, Madre de Dios, MUSM 7840 (15, CP 38,5 - 65,2mm); lago Valencia, Tambopata, MUSM 25553 (1, CP 58,7mm); cerca de $15 \mathrm{Km}$ abaixo a confluência dos rio Tambopata e Madre de Dios, aprox. 12³0'S, 6908'50”, USNM 263850 (CP 80,8mm); próximo a Pakitza, Parque Nacional Manu, USNM 295633 (4, CP 49,8 - 72,0mm); lago próximo ao riacho Pachija, Parque Nacional Manu, USNM 317776 (CP 73,0mm); Ucayali: rio Ucayali, Romainecocha, Pucallpa, MUSM 338 (10, CP 54,3 $65,0 \mathrm{~mm})$; rio Ucayali, Utuquinia, Ucayali, MUSM 515 (8, CP $60,0-84,2 \mathrm{~mm}$ ); rio Tamaya, Pucallpa, MUSM 1674 (5, CP 55,5 - 71,9mm); rio Ucayali, Pucallpa, MHNG 2189.44 (3, 37,8 $41,0 \mathrm{~mm} \mathrm{CP}$ ); rio Aguaytia, 60Km sudoeste de Pucallpa, MNHG 2092-65-68 (4, CP 77,2 - 89,3 mm). BRASIL, Acre: lago Pirapora, alfuente do rio Purus, próximo a Rio Branco, $10^{\circ} 03^{\prime} 02$ "S, 67 50 '53”'W, MCP 28646 (CP 84,8 mm); lago Esperança, rio Tarauacá, Tarauacá, MZUSP 34713 (19, CP 36,0 - 83,1mm); lago do Breu, rio Juruá, 09²2'00”S, 72²5’00”'W, MZUSP 50292 (CP 88,5 mm); rio Bagé, bacia do rio Juruá, 08 55'00”'S, 72²0'00"W, MZUSP 50293 (2, CP 84,3 - 96,1mm); rio São João, bacia do rio Juruá, $09^{\circ} 13^{\prime} 00^{\prime \prime}$ ', $72^{\circ} 35^{\prime} 00^{\prime \prime W}$, MZUSP 50294 (CP 83,3mm); lago Maranguape, rio Tejo, bacia do rio Juruá, 0902'00”S, 72²5'00”W, MZUSP 50295 (CP 72,0mm); Rondônia: rio Mamoré, próximo a Guajará-Mirim, INPA 16163 (5, CP 47,4 - 82,2mm); rio Madeira, Pimenta Bueno, INPA 16167 (5, CP 50,1 - 71,9mm); cachoeira do Teotônio, rio Madeira, 08'52'09'S, 64'04'00'W, MZUSP 34707 (4, CP 44,0 - 69,9mm); córrego Gengibre, rio das Mortes, estrada para Vila Berrante, MZUSP 34170 (CP 48,0mm); Amazonas: rio Machado, Jiparaná, acima de Nazaré, INPA 16168 (11, CP 27,7 - 91,3mm); lago Terra Preta, Janauari, 3º'13'S, 6001'W, MCP 27967 (2, CP
$38,8-60,4 \mathrm{~mm})$; rio Solimões, ilha Icé, Alvarães, 03¹6’36"S 64\%41'1"W, MCP 29988 (9, CP 53,9-91,4mm); lago Tefé, comunidade Nogueira, Tefé, $03^{\circ} 17^{\prime} 58^{\prime \prime} \mathrm{S}, 64^{\circ} 46^{\prime} 21^{\prime \prime W}, \mathrm{MCP}$ 29989 (CP 102,5mm); rio Solimões, margem direita da ilha Icé, Tefé, 03¹4'07"S, 6441'09'W, MCP 29990 (CP 69,2mm); lago Tefé, comunidade Nogueira, Tefé, $03^{\circ} 17^{\prime} 58^{\prime \prime}$, $64^{\circ} 46^{\prime} 21^{\prime \prime}$, MCP 29991 (CP 67.7 mm); boca do Ituxi, bacia do rio Purus, $07^{\circ} 19^{\prime} 00^{\prime \prime} \mathrm{S}, 64^{\circ} 51^{\prime} 00^{\prime \prime} \mathrm{W}$, MZUSP 20520 (CP 78,0mm); rio Purus, Açaituba, 0701'00"S, 64³5'00"W, MZUSP 20527 (CP $82,0 \mathrm{~mm}$ ); rio Madeira, foz do rio Machado, MZUSP 33434 (2, CP 70,6 - 80,7mm); rio Madeira, Calama, MZUSP 34705, (89, CP 31,7 - 92,7mm, 2 CP 61,0 e 77,0mm d\&c); rio Madeira, boca do [rio] Machado, MZUSP 34708 (3, CP 56,5-68,2mm); rio Madeira, Calama, MZUSP 34709 (3, CP 71,1 - 73,5mm, 1 CP $75,0 \mathrm{~mm}$ d\&c); igarapé Joari, Humaitá, bacia do rio Madeira, MZUSP 35543 (4, CP 42,4 - 74,0mm); rio Solimões, próximo a Fonte Boa, MZUSP 41072 (3, CP 48,0 - 56,5mm); boca do rio Acre, bacia do rio Purus, $08^{\circ} 44^{\prime} 00^{\prime \prime} S, 6^{\circ} 24^{\prime} 00^{\prime \prime} \mathrm{W}$, MZUSP 49514 (2, CP 55,2 - 59,7mm); rio Acre, $08^{\circ} 44^{\prime} 00^{\prime \prime} \mathrm{S}, 67^{\circ} 24^{\prime} 00^{\prime \prime} \mathrm{W}$, MZUSP 49605 (12, CP 61,1 - 76,6mm); lago Puraquequara, margem esquerda do rio Amazonas, MZUSP 53652 (1, CP 48,3 $\mathrm{mm})$; rio Purus, $8,5 \mathrm{Km}$ baixo do lago Tomé, $03^{\circ} 44^{\prime} 17^{\prime} \mathrm{S}$, $61^{\circ} 27^{\prime} 37^{\prime} \mathrm{W}$, MZUSP 55789 (CP 54,1mm); rio Amazonas, Itacotiara, MZUSP 77552 (CP 49,8mm); rio Roosevelt, acima da cachoeira, Panelas, bacia do rio Madeira, 09 $11^{\prime} 29^{\prime \prime} S$, 6045'29'W, MZUSP 77280 (CP 72,6 mm); rio Machado, sistema do rio Madeira, MZUSP 76186 (9, CP 45,0 - 57,4mm); Camaleão, ilha de Marchantaria, MZUSP não numerado, PB292 (CP 44,9mm); Paraná de Janauacá, entrada do lago do Castanho, MZUSP não numerado PB315 (CP 53,4mm); Camaleão, ilha de Marchantaria, MZUSP não numerado PB330 (CP 41,2mm); ressaca da ilha Marchantaria, MZUSP não numerado PB333 (CP 49,0mm d\&c); paraná de Janauacá, entrada do lago do Castanho, MZUSP não numerado $\mathrm{PB}$ (cal 2) (3, CP 42,0 - 48,3mm); Paraná de Janauacá, entrada do lago do Castanho, MZUSP não numerados PB357 (CP 54,1mm); Roraima: rio Uraricoera, igarapé na fazenda Canadá, bacia do rio Branco, $03^{\circ} 28^{\prime} 00^{\prime} \mathrm{N}, 60^{\circ} 58^{\prime} 00^{\prime} \mathrm{W}$, MZUSP 20231 (CP 44,2mm); rio Branco, Boa Vista, 02 ${ }^{\circ} 50^{\prime} 00^{\prime \prime} \mathrm{N}$, $60^{\circ} 40^{\prime} 00^{\prime \prime} \mathrm{W}$, MZUSP 20240 (4, CP 29, 6 - 62,3mm); cachoeira do Bem Querer, Rio Branco, MZUSP 34714 (45, CP 49,7 - 68,9 $\mathrm{mm}$ ); rio Uraricoera, Maracá, bacia do rio Branco, MZUSP 34715 (7, CP 72,7 - 93,3mm); rio Branco, Marará, 01³0’00”N, $61^{\circ} 16$ '00”'W, MZUSP 34716 (13, CP 36,1 - 55,7mm); rio Branco, abaixo de Virua, $01^{\circ} 16^{\prime} 44^{\prime \prime} S, 61^{\circ} 50$ '32”W, MZUSP 55787 (20, CP 34,5 - 8,6mm); Pará: rio Amazonas, ilha de São Miguel,

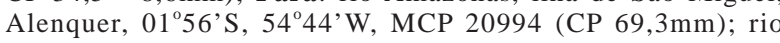
Tocantins, Icangui, INPA 16164 (20, CP 29,8 - 77,1mm); rio Tocantins, Icangui, INPA 16166 (2, CP 76,0 - 86,0 mm); rio Tocantins, Icangui, INPA 16183 ( $3, \mathrm{CP} 76,4-94,2 \mathrm{~mm})$; rio Tocantins, Itupiranga, INPA 16186 (13, CP 39,5 - 61,1mm); lagoas na margem do rio Tocantins, próximo a Tucurui, MZUSP 20373 (4, CP 61,0 - 86,0mm); igarapé Muru, rio Tocantins, MZUSP 20650 (CP 81,3mm); Oriximiná, MZUSP 88003 (CP 60,3mm); rio Paituna, Monte Alegre, MCP 29307 (5, CP 58,2 $78,6 \mathrm{~mm}$ ); lago Supiá em frente de Codajás, MZUSP 88004 (CP $36,3 \mathrm{~mm}$ ); Goiás: rio Bagagem, próximo a confluência com o rio Maranhão, Niquelândia, MCP 15879 (CP 55,0mm); lagos do rio Araguaia, próximo a Luiz Alves, $13^{\circ} 14^{\prime} \mathrm{S}, 50^{\circ} 35^{\prime} \mathrm{W}$, MCP 17217 (7, CP 62,0 - 75,4mm); rio Araguaia, MZUSP 19346 (CP $55,7 \mathrm{~mm}$ ); rio Tocantins, porto do Rubão, $13^{\circ} 44^{\prime} 31^{\prime \prime} \mathrm{S}$ 48 8'29"'W, MCP 19772 (43, CP 26,0 - 80,1mm); rio Tocantins, a $3 \mathrm{Km}$ do eixo da barragem UHE Serra da Mesa, 13 $3^{\circ} 50^{\prime} 51^{\prime \prime} \mathrm{S}$, 4816’60”'W, MCP 20223 (9, CP 32,4 - 58,6mm); lagoa do Imbú, margem direita do rio Paranã, bacia do rio Tocantins, MZUSP 40420 (12, CP 51,3 - 66,1mm); rio Araguaia, Aruanã, MZUSP 4842 (37, CP 36,0 - 67,0mm); lago Dumba Grande, bacia do rio Araguaia, Barra da Garça, MZUSP 42784 (3, CP 40,8 - 52,6mm); Tocantins: rio Tocantins, logo abaixo da UHE Lageado, 9 $45^{\prime} 02^{\prime \prime} \mathrm{S}-48^{\circ} 21^{\prime} 56^{\prime \prime} \mathrm{W}$, UNT 162 (3, CP 59,7 - 63,6mm); rio Crixás, Brejinho do Nazaré, $11^{\circ} 03$ 'S, 48 38'W, UNT 163 (3, CP 73,3 - 78,0mm); lagoa Pedra do Santo, Brejinho do Nazaré, $11^{\circ} 01^{\prime} \mathrm{S}, 48^{\circ} 34^{\prime} \mathrm{W}$, UNT $164(\mathrm{CP} 95,8 \mathrm{~mm})$; rio Tocantins, Brejinho do Nazaré, 1059'46”'S, 48 32'06”W, UNT 165 (2, CP 47,8 - 52,5mm); córrego São João, Palmas, $10^{\circ} 23^{\prime} \mathrm{S}, 48^{\circ} 26^{\prime} \mathrm{W}$ UNT 167 (2, CP 65,7 - 69,5mm); lagoa Pedro do Santo, Brejinho 
do Nazaré, $11^{\circ} 01^{\prime} \mathrm{S}, 48^{\circ} 34^{\prime} \mathrm{W}$, UNT 168 (CP 68,0mm); rio Tocantins, fazenda Traçadal, Paranã, $12^{\circ} 29^{\prime} \mathrm{S}, 48^{\circ} 12^{\prime} \mathrm{W}$, UNT 169 (2, CP 72,1 - 74,2mm); rio Paranã, fazenda Traçadal, $12^{\circ} 30^{\prime} \mathrm{S}$, $48^{\circ} 12^{\prime} \mathrm{W}$, UNT $170(\mathrm{CP} 76,1 \mathrm{~mm})$; rio Tocantins, Porto Nacional, 1043'15”S, 48²5'14”W, UNT 171 (3, 59,9 - 70,2mm); lagoa Capivara, Brejinho do Nazaré, $11^{\circ} 01^{\prime}$ 'S, 48 $35^{\circ} \mathrm{W}$, UNT 172 (CP $101,1 \mathrm{~mm})$; lagoa Capivara, Brejinho do Nazaré, $11^{\circ} 1^{\prime} \mathrm{S}, 48^{\circ} 35^{\prime} \mathrm{W}$, UNT 173 (CP 72,4mm); lagoa Dionizio, Peixe, 11 ${ }^{\circ} 44^{\prime} 49$ ”S, 48 38'16"W, UNT 174 (3, CP 61,6 - 79,9mm); Mato Grosso: rio Cuiabá, Volta Grande, Santo Antonio do Leverger, MZUSP 14737 (CP 55,9mm); idem anterior, MZUSP 14738 (CP $65,8 \mathrm{~mm})$; idem anterior MZUSP 14739 (CP 70,1 mm); rio Paraguai, Cáceres, MCP 15705 (2, CP 63,8 - 69,8mm); bacia do rio ribeirão Cascalheira, rio Araguaia, Santa Terezinha, MZUSP 19643 (3, CP 47,5 - 50,9mm); rio Paraguai, baía Bela ou Albuquerque, Corumbá, MZUSP 20412 (5, CP 96,4 - 118,5mm, 1 CP 91,0mm d\&c); rio Cuiabá, Volta Grande, Santo Antonio do Leverger, MZUSP 27689 (CP 98,0mm); Rio Grande do Sul: rio Uruguai, Uruguaiana, MCP 12018 (CP 90,5mm); foz do rio Ijui-Mirim, Pirapó, MCP 12390 (3, CP 92,5 - 111,5mm, 1 CP 98,0mm d\&c); rio Uruguai, rancho da Amizade, São Borja, MCP 12445 (CP 108,3mm); rio Uruguai, porto de Santo Izidro, São Nicolau, MCP 12650 (3, CP 95,0 - 120,3mm); rio Uruguai, porto de Santo Izidro, São Nicolau, MCP 13066 (CP 129,1mm); barra do rio Ijuí, Roque Gonzales, MCP 13220 (CP 116,7mm). BOLIVIA, Beni: rio Matos, bacia do rio Apere, INHS 37029 (3, CP 35,7 - 65,2mm); rio Ibare, cerca de $17 \mathrm{Km}$ sudoeste de San Lorenzo, Marban, UF 82089 (CP 62,8mm); rio Ibaré, Puerto Almecen, 14 53'0"S, 6456'0"W, UF 82061 (CP 81,0mm); rio Ibare cerca de $5 \mathrm{~km}$ ao norte de Puerto Almacén, Cercado, 1449'0"S, 6458'0"W, UF 82528 (8, CP 52,3 - 87,1mm); rio Ibaré $5 \mathrm{~km}$ ao norte de Puerto Almecen, Cercado, 14\%49'0”S, 645ㅇ' ${ }^{\circ}$ 'W, UF 82529 (4, CP 45,9 - 57,0mm); rio Madre de Dios, Laguna San Luis, cerca de $80 \mathrm{Km}$ acima de Riberalta, MZUSP 35947 (2, CP 91,7 - 96,6mm); rio San Martin, povoado California, bacia do rio Mamoré, 13²0'17'S, 6327'26”W, UMSS 0219 (5, CP 76,4 - 89, 2mm); rio Matos, Ballivia, drenagem do rio Mamoré, $14^{\circ} 55^{\prime} \mathrm{S}, 66^{\circ} 17^{\prime} \mathrm{W}$, USNM 384395 (20, CP 42,7 $66,3 \mathrm{~mm})$; Cochabamba: rio Chaparé, Todos Santos, ANSP 69306 (CP 48,2mm); laguna Yuca, Carrasco, sistema do rio Mamoré, 1646'38'S, 6447'49'W, MCP 35412 (2, CP 59,4 $86,9 \mathrm{~mm})$; confluência do rio Chaparé com o rio Coni, cerca de $10 \mathrm{Km}$ além de Todos los Santos, MHNG 2232.6 (4, CP 86,2 $110,7 \mathrm{~mm})$; rio Mamoré, Cachuela, $10^{\circ} 48^{\prime} 24^{\prime \prime} \mathrm{S}, 65^{\circ} 24^{\prime} 36^{\prime} \mathrm{W}$, UMMZ 205075 (7, CP 49,8 - 80,2mm); rio Beni, Rurrenabaque, UMMZ 66443 (5, CP 54,3 - 90,9mm); lagoas ao longo do rio Ichilo, próximo a confluência com o rio Chapare, $64^{\circ} 36^{\prime} \mathrm{S}$, $16^{\circ} 57^{\prime} \mathrm{W}$, UMSS 0218 (24, CP 87,6 - 114,3mm); laguna Bufeos, várzea do rio Ichilo, sistema do rio Mamoré, aprox. $43 \mathrm{Km}$ abaixo de Puerto Villaroel, 16 26'07'S, 6442'20'W, UMSS 0221 (7, CP 52,7 - 62,9mm). PARAGUAI, Alto Paraguay: rio Paraguai, estância Doña Julia, Bahia Negra, NRM 33344 (CP 67,2 mm); idem anterior, NRM 33405 (CP 42,0mm); Central: rio Paraguai, baia de Assunção, MCP 12320 (CP 117,9mm); rio Paraguai, Villeta, MHNP 816 (6, CP 39,0 - 117,4mm); Misiones: rio Tebicuary, Cento-Cué, Villa Florida, NRM 22825 (3, CP 99,2 - 117,7mm); rio Tebicuary, Cento-Cué, NRM 52348 (2, CP 85,5 $-105,6 \mathrm{~mm})$.

Diagnose. Difere de Roeboides biserialis, $R$. descalvadensis, $R$. sazimai sp. nov. e $R$. xenodon pelo número elevado de escamas na linha lateral, 69 a 87, versus 55 a 71. De Roeboides descalvadensis pelo maior comprimento do focinho em relação ao CP (Fig. 2). Difere de Roeboides xenodon por ter 15 a 23 escamas acima da linha lateral e 12 a 19 abaixo da linha lateral versus, respectivamente, 10 a 15 e 10 a 13. Difere ainda de $R$. biserialis por possuir apenas uma fileira de dentes no dentário, versus duas. De Roeboides numerosus e $R$. xenodon difere pelo número de rastros branquais no primeiro arco, 8 a 11 (8 e 11 somente na população do Suriname), versus, respectivamente, 12 a 14 e 7 a 8 ; de $R$. oligistos pelo elevado número de raios da nadadeira anal, 42 a 54 , versus 38 a 44 e pela presença das manchas umeral e caudal, versus ausência.

Descrição. Dados morfométricos nas Tabelas I e II. Corpo alto. Perfil dorsal elevado a partir da base do processo supra-occipital até a origem da nadadeira dorsal, leve declive ao longo da base desta nadadeira, continuando-se reto até o pedúnculo caudal. Perfil ventral convexo até a origem na nadadeira anal, reto a partir deste ponto até o pedúnculo caudal. Boca subterminal.

Focinho com perfil superior reto, ultrapassando a maxila inferior. Maxilar longo, extremidade posterior atingindo a vertical que passa pelo meio do olho, com cinco a 13 dentes, os dois, ou três, primeiros, pequenos, cônicos, seguidos, nos adultos, de um ou dois dentes mamiliformes desenvolvidos, deslocados para a superfície externa do osso; os restantes mamiliformes localizados na borda do osso. Pré-maxilar com três dentes mamiliformes externos sem cúspides: um, anterior, desenvolvido, e dirigido para frente (corresponde ao dente D1 em LuCENA, 1998), outro localizado no ramo lateral e dirigido para fora (corresponde ao dente D2 em LuCEnA, 1998), e o terceiro, acima do dente D2, dirigido para frente e para fora (correspondente ao dente D3 em Lucena, 1998); D2 e D3 menores que o D1. Mais internamente, os dentes não possuem arranjo ou número definidos, diferindo, inclusive, de um pré-maxilar para outro; na disposição mais constante ocorre uma fileira com quatro a seis dentes mamiliformes, desalinhados, que acompanha a borda interna do pré-maxilar, o terceiro, ou quarto, dente mais desenvolvido e dirigido para frente; a seguir há dois dentes mamiliformes, posicionados próximos a junção entre os dois pré-maxilares, seguido por um hiato e, na porção final do ramo lateral do prémaxilar, uma fileira de três a cinco dentes cônicos pequenos. Dentário com dois dentes mamiliformes externos sem cúspides, um anterior dirigido para frente (correspondente ao dente D4 em LuCENA, 1998) e outro em posição lateral, e num plano mais inferior em relação ao D4, dirigido para fora (corresponde ao dente D5 em LuCENA,

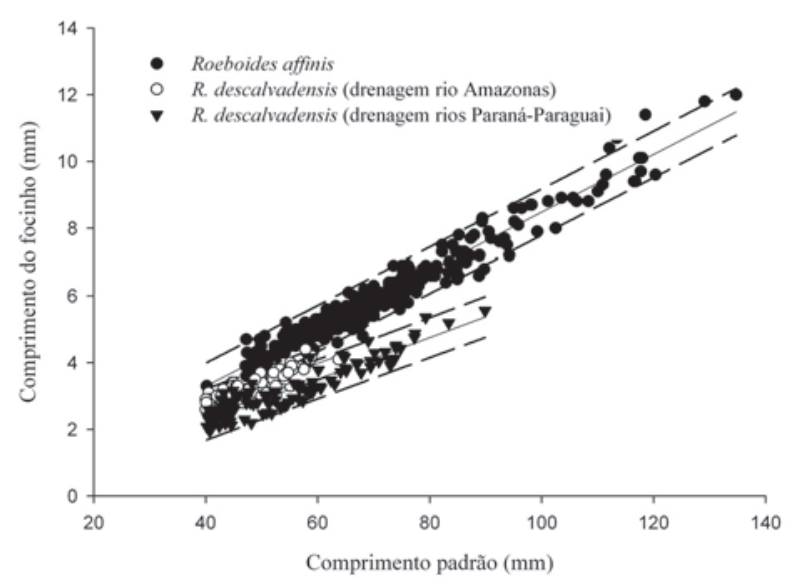

Fig. 2. Regressões do comprimento do focinho em relação ao comprimento padrão de Roeboides descalvadensis (populações das drenagens do rio Amazonas e dos rios Paraguai-Paraná) e $R$. affinis. Linhas tracejadas representam os intervalos de confiança de $95 \%$. 
1998); margem do dentário com um dente sinfiseal mamiliforme, grande, seguido de quatro a seis dentes cônicos ou mamiliformes menores e um mamiliforme grande, geralmente dirigido para fora; seguido por uma série de sete a nove pequenos dentes cônicos de base larga. Dentes sinfiseanos com duas pequenas cúspides, às vezes ausentes, em sua superfície interna, os demais sem cúspides. Rastros branquiais, quatro a oito no ramo superior $(\mathrm{n}=478$, média=6,0), oito a 11 no inferior ( $\mathrm{n}=484$, média=9,5), oito e 11 somente em exemplares da Guiana e Suriname.

Nadadeira dorsal, i+9 raios, sua origem na vertical que passa pela origem da origem da nadadeira anal ou

Tabela I. Dados morfométricos de Roeboides affinis e R. biserialis (m, média; n, número de exemplares; SD, desvio padrão; A, holótipo de $R$. bicornis, ANSP 8151; B, lectótipo de $R$. affinis BMNH 1867.6.13.62; C, Paralectótipo de R. affinis, BMNH 1867.6.13.61; D, lectótipo de R. biserialis, MCZ 21335).

\begin{tabular}{|c|c|c|c|c|c|c|c|c|c|c|c|c|c|c|}
\hline \multirow[b]{3}{*}{ Medidas } & \multirow[t]{3}{*}{ A } & \multirow[t]{3}{*}{ B } & \multirow[t]{3}{*}{$\mathrm{C}$} & \multirow[b]{3}{*}{$\mathrm{n}$} & \multirow{2}{*}{\multicolumn{2}{|c|}{$\begin{array}{c}\text { R. affinis } \\
\text { Limites }\end{array}$}} & \multirow[b]{3}{*}{$\mathrm{m}$} & \multirow[b]{3}{*}{ SD } & \multirow[t]{3}{*}{$\mathrm{D}$} & \multirow[b]{3}{*}{$\mathrm{n}$} & \multirow{2}{*}{\multicolumn{2}{|c|}{$\begin{array}{c}R . \text { biserialis } \\
\text { Limites }\end{array}$}} & \multirow[b]{3}{*}{$\mathrm{m}$} & \multirow[b]{3}{*}{ SD } \\
\hline & & & & & & & & & & & & & & \\
\hline & & & & & Min. & Máx. & & & & & Min. & Máx. & & \\
\hline Compr. padrão (mm) & 53,6 & 83,6 & 74,4 & 119 & 48,4 & 134,7 & 76,6 & 20,344 & 43,0 & 33 & 33,2 & 57,9 & 45,1 & 7,365 \\
\hline \multicolumn{15}{|c|}{ Porcentagens do comprimento padrão } \\
\hline Altura do corpo & 32,5 & 33,1 & 40,7 & 119 & 31,1 & 47,8 & 35,9 & 2,484 & 38,6 & 32 & 34,0 & 39,1 & 36,6 & 1,523 \\
\hline Compr. pré-dorsal & & 52,3 & 55,2 & 119 & 37,4 & 54,2 & 51,0 & 1,721 & 47,7 & 33 & 47,2 & 53,7 & 51,0 & 1,393 \\
\hline Compr. pré-anal & & 42,6 & 49,0 & 119 & 46,0 & 52,7 & 49,0 & 1,228 & 43,2 & 33 & 42,9 & 137,3 & 49,5 & 15,861 \\
\hline Compr. pré-peitoral & & 27,6 & 27,8 & 119 & 25,3 & 30,6 & 27,9 & 0,986 & 28,6 & 33 & 25,5 & 29,5 & 27,5 & 0,990 \\
\hline Compr. pré-ventral & & 34,3 & 35,0 & 119 & 34,1 & 39,9 & 37,0 & 1,067 & 36,0 & 32 & 34,1 & 38,6 & 36,3 & 1,125 \\
\hline Compr. ped. caudal & 8,4 & 8,0 & 8,7 & 117 & 6,0 & 11,8 & 9,5 & 1,001 & 8,1 & 31 & 7,6 & 10,0 & 8,6 & 0,631 \\
\hline Altura ped. caudal & 6,0 & 6,2 & 8,3 & 117 & 6,8 & 9,1 & 8,0 & 0,489 & 7,9 & 32 & 6,0 & 8,5 & 7,7 & 0,602 \\
\hline Compr. cabeça & & 28,6 & 27,9 & 119 & 25,5 & 30,9 & 28,1 & 1,062 & 27,0 & 32 & 24,7 & 28,9 & 26,8 & 0,851 \\
\hline \multicolumn{15}{|c|}{ Porcentagens do comprimento da cabeça } \\
\hline Compr. focinho & & 30,5 & 31,7 & 118 & 26,6 & 36,1 & 30,2 & 1,578 & 20,7 & 32 & 19,4 & 28,7 & 24,1 & 2,481 \\
\hline Diametro órbita & & 23,3 & 27,4 & 117 & 23,6 & 36,5 & 29,8 & 2,482 & 34,5 & 32 & 28,9 & 38,5 & 34,9 & 2,079 \\
\hline Compr. maxila & & 48,5 & 45,6 & 119 & 40,3 & 52,3 & 48,4 & 1,918 & 50,0 & 32 & 39,8 & 50,0 & 44,6 & 3,069 \\
\hline Espaço inter-orbital & & 24,3 & 27,9 & 119 & 21,8 & 30,3 & 26,6 & 1,415 & 26,7 & 32 & 24,2 & 29,5 & 27,4 & 1,238 \\
\hline
\end{tabular}

Tabela II. Dados morfométricos de Roeboides affinis individualizados por drenagens (m, média; n, número de exemplares).

\begin{tabular}{|c|c|c|c|c|c|c|c|c|c|c|c|c|c|c|c|c|c|c|c|c|}
\hline \multirow[b]{3}{*}{ Medida } & \multirow[b]{3}{*}{$\mathrm{n}$} & \multicolumn{3}{|c|}{ Amazonas } & \multicolumn{4}{|c|}{ Paraguai } & \multicolumn{4}{|c|}{ Tocantins/Araguaia } & \multicolumn{4}{|c|}{ Orinoco } & \multicolumn{4}{|c|}{ Guiana/Suriname } \\
\hline & & \multicolumn{3}{|c|}{ Limites } & \multicolumn{4}{|c|}{ Limites } & \multicolumn{4}{|c|}{ Limites } & \multicolumn{4}{|c|}{ Limites } & \multicolumn{4}{|c|}{ Limites } \\
\hline & & $\min$ & máx & $\mathrm{m}$ & $\mathrm{n}$ & $\min$ & máx & $\mathrm{m}$ & $\mathrm{n}$ & $\min$ & máx & $\mathrm{m}$ & $\mathrm{n}$ & $\min$ & máx & $\mathrm{m}$ & $\mathrm{n}$ & $\min$ & máx & $\mathrm{m}$ \\
\hline Compr. & 127 & 47,0 & 102,5 & 73,4 & 33 & 55,9 & 134,7 & 99,0 & 44 & 47,2 & 101,1 & 68,3 & 36 & 48,3 & 84,5 & 60,5 & 33 & 40,2 & 89,4 & 71,4 \\
\hline \multicolumn{21}{|c|}{ Porcentagens do comprimento padrão } \\
\hline $\begin{array}{l}\text { Altura do } \\
\text { corpo }\end{array}$ & 127 & 31,1 & 42,9 & 36,2 & 33 & 32,2 & 47,8 & 36,8 & 44 & 31,3 & 38,7 & 35,1 & 36 & 33,1 & 38,6 & 35,9 & 33 & 31,2 & 38,4 & 35,8 \\
\hline $\begin{array}{l}\text { Compr. } \\
\text { pré-dorsal }\end{array}$ & 127 & 37,4 & 54,6 & 50,8 & 33 & 48,8 & 54,2 & 50,9 & 44 & 48,3 & 52,5 & 50,5 & 36 & 49,0 & 53,9 & 51,5 & 33 & 48,9 & 52,2 & 50,5 \\
\hline $\begin{array}{l}\text { Compr. } \\
\text { pré-anal }\end{array}$ & 127 & 41,0 & 52,7 & 48,8 & 33 & 46,0 & 52,9 & 48,7 & 44 & 45,9 & 51,4 & 48,8 & 36 & 45,9 & 50,6 & 48,8 & 33 & 45,7 & 51,2 & 47,7 \\
\hline $\begin{array}{l}\text { Compr. } \\
\text { pré-peit. }\end{array}$ & 127 & 25,8 & 30,6 & 28,0 & 33 & 25,3 & 29,6 & 27,5 & 44 & 26,0 & 35,6 & 28,2 & 36 & 26,5 & 30,4 & 28,2 & 33 & 26,6 & 29,7 & 27,9 \\
\hline $\begin{array}{l}\text { Compr. } \\
\text { pré-ventral }\end{array}$ & 127 & 31,4 & 39,9 & 36,9 & 33 & 34,1 & 38,6 & 36,5 & 42 & 30,4 & 38,6 & 36,5 & 36 & 34,5 & 39,5 & 37,1 & 33 & 34,7 & 38,8 & 36,5 \\
\hline $\begin{array}{l}\text { Compr. } \\
\text { ped. caud. }\end{array}$ & 126 & 6,0 & 11,8 & 9,3 & 31 & 7,7 & 11,1 & 9,8 & 44 & 6,7 & 11,5 & 9,4 & 36 & 7,2 & 11,5 & 9,3 & 31 & 8,1 & 10,5 & 9,2 \\
\hline $\begin{array}{l}\text { Altura } \\
\text { ped. caud. }\end{array}$ & 125 & 6,8 & 8,9 & 7,9 & 32 & 7,3 & 9,1 & 8,4 & 44 & 6,6 & 11,7 & 7,9 & 36 & 7,0 & 8,6 & 7,8 & 33 & 6,8 & 8,6 & 7,9 \\
\hline Compr. & 127 & 25,7 & 31,0 & 28,2 & 33 & 25,5 & 29,6 & 27,4 & 44 & 26,9 & 30,6 & 28,7 & 36 & 26,1 & 30,4 & 28,6 & 33 & 26,8 & 29,9 & 28,5 \\
\hline \multicolumn{21}{|c|}{ Porcentagens do comprimento da cabeça } \\
\hline $\begin{array}{l}\text { Compr. } \\
\text { focinho }\end{array}$ & 126 & 24,3 & 32,4 & 29,6 & 33 & 27,7 & 36,1 & 31,2 & 44 & 24,7 & 31,8 & 28,5 & 36 & 26,6 & 32,2 & 29,6 & 33 & 27,6 & 33,2 & 29,5 \\
\hline $\begin{array}{l}\text { Diametro } \\
\text { órbita }\end{array}$ & 126 & 23,6 & 36,5 & 28,8 & 31 & 26,3 & 33,2 & 29,7 & 44 & 25,6 & 32,3 & 29,3 & 36 & 25,9 & 33,0 & 30,1 & 31 & 27,3 & 34,6 & 30,3 \\
\hline $\begin{array}{l}\text { Compr. } \\
\text { maxila }\end{array}$ & 127 & 40,3 & 53,5 & 48,1 & 33 & 46,7 & 52,3 & 49,4 & 44 & 44,5 & 50,9 & 48,1 & 36 & 45,3 & 52,0 & 48,5 & 33 & 25,4 & 52,8 & 48,4 \\
\hline $\begin{array}{l}\text { Espaço } \\
\text { inter-orb. }\end{array}$ & 127 & 21,8 & 29,0 & 26,4 & 33 & 23,3 & 30,3 & 27,0 & 44 & 22,6 & 28,4 & 25,0 & 36 & 23,3 & 28,5 & 26,3 & 33 & 23,7 & 27,2 & 25,6 \\
\hline
\end{tabular}


levemente atrás. Nadadeira peitoral, i+12 a 15 raios [12] $(\mathrm{n}=445$, média $=12,6)$, seu raio mais longo geralmente não alcançando a origem da nadadeira anal, podendo alcançar em exemplares pequenos. Em geral, exemplares entre 24,8 a 30,1mm CP(MCP 19772, INHS 53882, INPA 16168, NRM 23745) apresentam nadadeira peitoral ainda na forma larval (mesmo que parcialmente). Mas podem ocorrer exceções: exemplares de 28,3mm CP (ROM 64136) da drenagem do rio Essequibo, Guiana e de $30,2 \mathrm{~mm}$ e $30,4 \mathrm{~mm}$ CP (INPA 1616) do rio Tocantins, possuem as nadadeiras peitorais totalmente formadas, enquanto no exemplar de $32,4 \mathrm{~mm}$ CP (ICN MHN 3868) da drenagem do rio Orinoco, elas ainda estão na forma larval. Nadadeira ventral, i+7 raios, seu raio mais longo ultrapassando a origem da nadadeira anal; machos com até dois ganchos ósseos por segmento presentes na metade superior da borda interna do primeiro ao sexto raio ramificado. Nadadeira anal, iv-v+42 a 54 raios [48] ( $\mathrm{n}=476$, média=47,9); machos com um gancho; ósseo por segmento, raramente dois ganchos, presentes na borda interna do último raio não ramificado até, no máximo, o $22^{\circ}$ raio ramificado. Nadadeira caudal furcada com $\mathrm{i}+17+\mathrm{i}$ raios principais. Escamas da linha lateral, 69 a 87 [aproximadamente 70] $(\mathrm{n}=448$, média $=75,6)$; escamas abaixo da linha lateral, 12 a 20 [aproximadamente 14] $(\mathrm{n}=475$, média $=15,4)$; escamas acima da linha lateral, $15 \mathrm{a}$ 23 [aproximadamente 17] $(\mathrm{n}=384$, média $=18,4)$; escamas ao redor do pedúnculo caudal, 18 a 28 [21] $(\mathrm{n}=312$ média=22,7). Trinta e oito vértebras totais, sendo $14 \mathrm{ou}$ 15 pré-caudais e 23 ou 24 caudais ( 4 exs. d\&c).

Coloração em álcool. Corpo claro, maioria dos exemplares com uma larga faixa prateada longitudinal desde a região imediatamente posterior ao canto superior do opérculo até o final do pedúnculo caudal. Margem distal do focinho escurecida; margem distal da maxila inferior podendo estar escurecida em alguns exemplares. Manchas umeral, pequena, conspícua ou reduzida a alguns cromatóforos, localizada na região pósterosuperior do pseudotímpano; mancha caudal geralmente presente, algumas vezes conspícua, sobre o pedúnculo caudal e estendendo-se sobre a base dos raios medianos da nadadeira caudal. Nadadeiras claras.

Distribuição. Ocorre nos sistemas dos rios Paraguaibaixo, Paraná-Uruguai, Amazonas, Orinoco, TocantinsAraguaia e rios na Guiana e Suriname (Fig. 3).

Variação geográfica. Merísticos. As populações aqui atribuídas a $R$. affinis distribuem-se amplamente pelos rios da América do sul cisandina (Fig. 3) e, não surpreendetemente, apresentam variação considerável nos caracteres merísticos analisados. Apesar da sobreposição ocorrida, verificam-se diferenças estatisticamente significativas no número de raios ramificados na nadadeira anal (Fig. 4; Tab. III) entre as populações do Paraguai, Purus e calha amazônica em relação a Branco, Orinoco e Tocantins-Araguaia e no número de rastros braquiais do ramo inferior do primeiro arco entre as populações do Tocantins-Araguaia e Guiana/ Suriname (Fig. 5). Tais resultados, no entanto, não parecem expressar espécies distintas, visto que a ampliação da análise à outras drenagens, mostra sobreposição dos valores. Especial atenção merece as variações ocorridas no número de escamas: perfuradas da linha lateral, acima e abaixo da linha lateral, e ao redor do pedúnculo caudal. Apesar da sobreposição das amplitudes e considerando somente a faixa de concentração dos $50 \%$ das contagens de escamas (correspondendo ao retângulo nas Figuras 6 a 9) - exceto as populações do Juruá e Purus que contribuíram com poucos exemplares (de dois a 12, dependendo da contagem) - verificamos que as populações analisadas dividem-se, grosso modo, em quatro grupos quanto ao número de escamas: reduzido, médio, alto e com amplitude de variação que abrange essas três categorias. Os três primeiros, no entanto, não formam conjuntos comuns, variando a constituição de acordo com a contagem considerada. Duas populações podem ser classificadas,

Tabela III. Resultados de Q (teste de Dunn's) para $\mathrm{P}<0,05$ entre os pares de médias do número de raios ramificados da nadadeira anal de 6 populações de Roeboides affinis (m, média).

\begin{tabular}{lccc}
\hline & $\begin{array}{c}\text { Calha amazônica } \\
(\mathrm{m}=49,2)\end{array}$ & $\begin{array}{c}\text { Paraguai } \\
(\mathrm{m}=49,4)\end{array}$ & $\begin{array}{c}\text { Purus } \\
(\mathrm{m}=49,1)\end{array}$ \\
\hline Branco $(\mathrm{m}=46,5)$ & 4,771 & 4,910 & 5,805 \\
Orinoco $(\mathrm{m}=46,4)$ & 5,404 & 5,571 & 6,598 \\
Tocantins-Araguaia & 3,616 & 3,698 & 4,304 \\
$(\mathrm{~m}=46,0)$ & & & \\
\hline
\end{tabular}

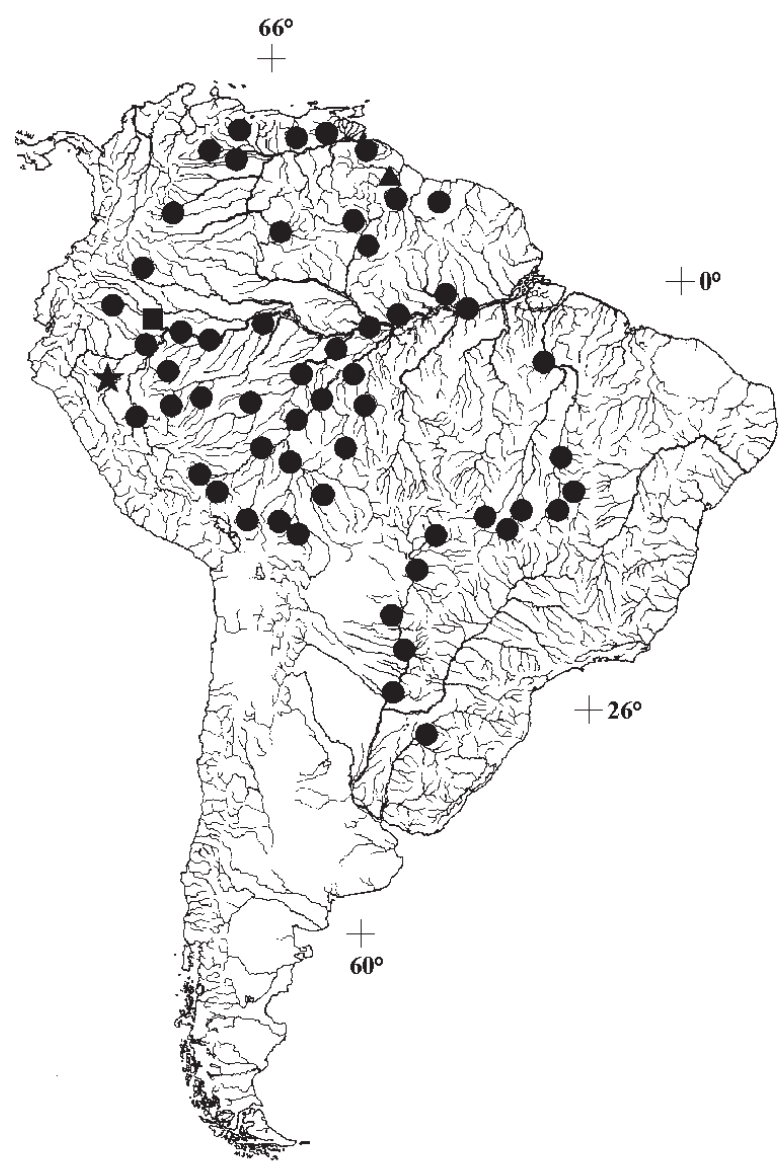

Fig. 3. Mapa com a distribuição de R. affinis (estrela, localidadetipo). Quadrado, localidade-tipo de Roeboides bicornis e triângulo localidade-tipo de $R$. thurni. Localidade-tipo de $R$. prognathus não especificada (rio Paraguai). Um sinal pode indicar mais de um local de coleta e/ou exemplares. 
em todas as contagens, no quarto grupo: Madeira e Paraguai abrangeram na faixa dos $50 \%$, respectivamente, uma ampla variação nos valores, portanto, não sendo possível classificar a população em um dos grupos acima e, valores que correspondem a um alto número de escamas. Devido ao fato de estudos prévios envolvendo essas bacias e o gênero Roeboides (grupo-microlepis) ter mostrado semelhante padrão de variação,

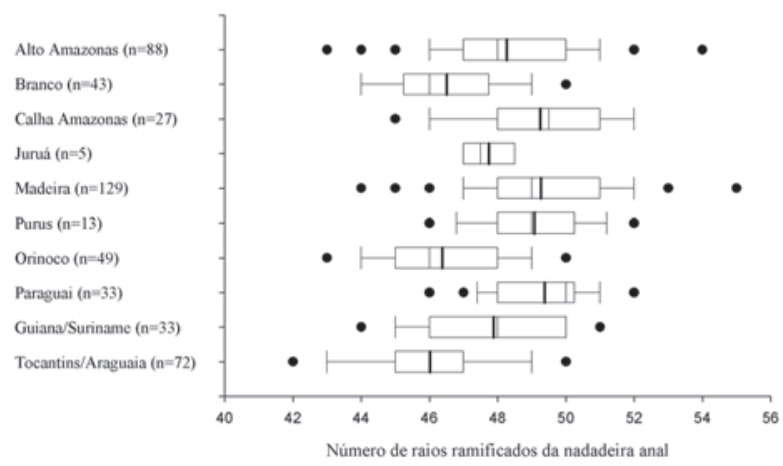

Fig. 4. Variação do número de raios ramificados da nadadeira anal entre as populações de Roeboides affinis. Traço fino no interior do retângulo corresponde à mediana enquanto o traço espesso à média.

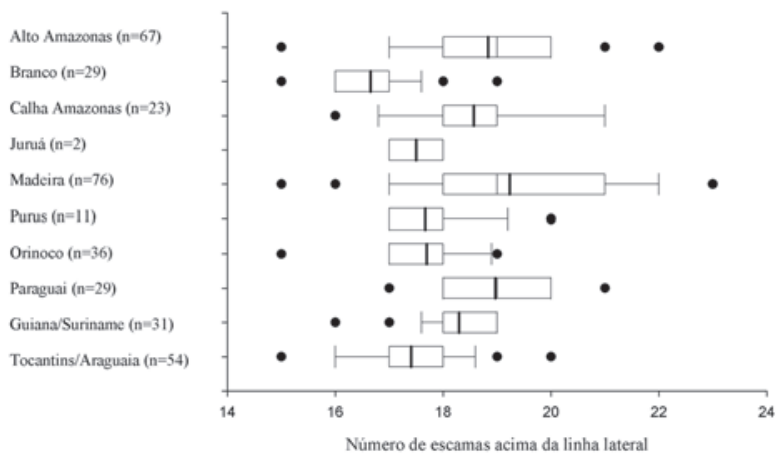

Fig. 6. Variação do número de escamas acima da linha lateral entre as populações de Roeboides affinis. Traço fino no interior do retângulo corresponde à mediana enquanto o traço espesso à média.

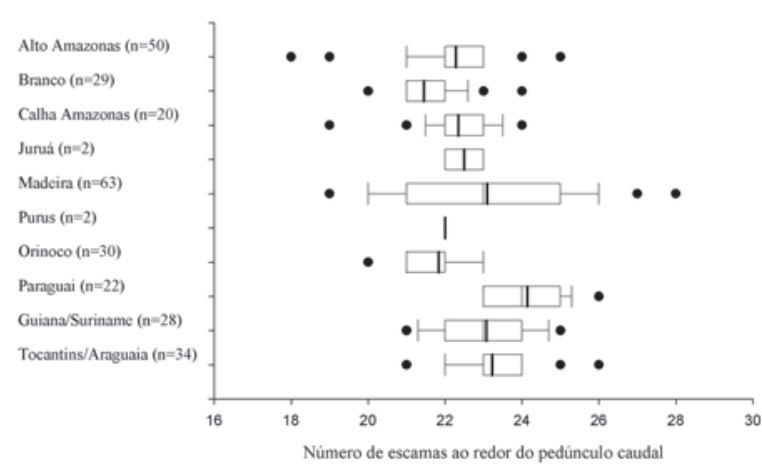

Fig. 8. Variação do número de escamas perfuradas ao redor do pedúnculo caudal entre as populações de Roeboides affinis. Traço fino no interior do retângulo corresponde à mediana enquanto o traço espesso à média. especialmente no número de escamas perfuradas da linha lateral (LuCENA, 2003), foi feita a distribuição da freqüência considerando somente esse caráter. A Fig. 10 mostra que a população do Madeira, de fato, possui tendência na formação de dois picos, um com a moda em 71 escamas e outro em 82. Em contrapartida a população do Paraguai apresenta a amplitude de variação de 78 a 85 escamas e moda em 78 escamas. Embora indivíduos com número

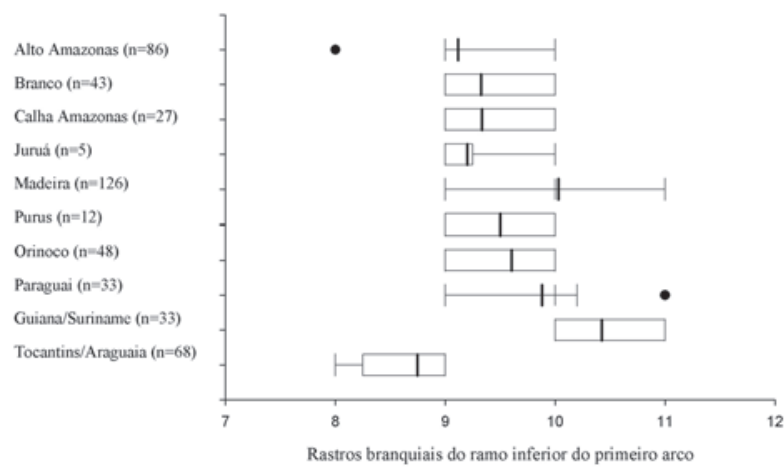

Fig. 5. Variação do número de rastros do ramo inferior do primeiro arco branquial entre as populações de Roeboides affinis. Traço fino no interior do retângulo corresponde à mediana enquanto o traço espesso à média.

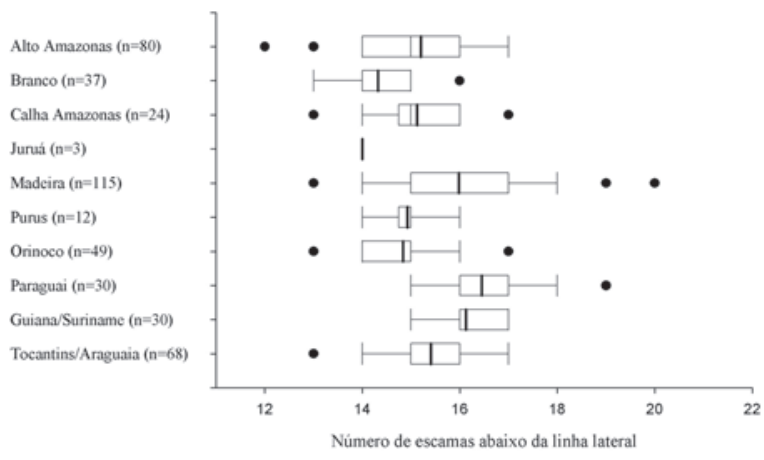

Fig. 7. Variação do número de escamas abaixo da linha lateral entre as populações de Roeboides affinis. Traço fino no interior do retângulo corresponde à mediana enquanto o traço espesso à média.

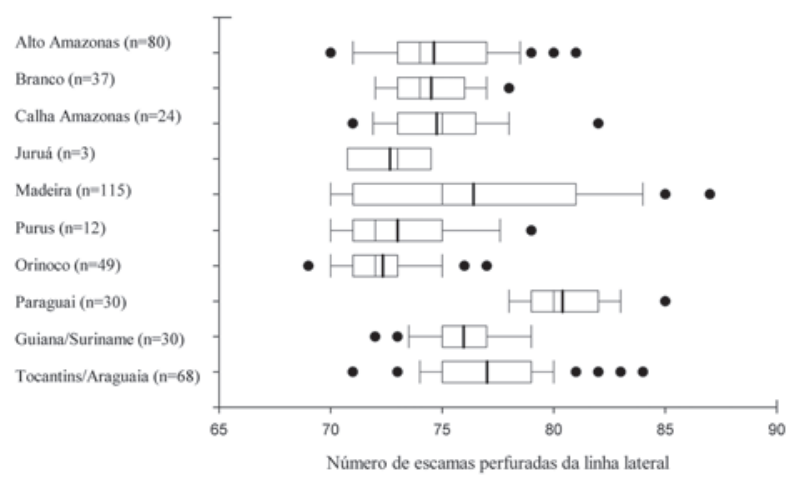

Fig. 9. Variação do número de escamas da linha lateral entre as populações de Roeboides affinis. Traço fino no interior do retângulo corresponde a mediana enquanto o traço espesso à média. 
elevado de escamas perfuradas, acima de 79, tenham ocorrido nas demais populações, com exceção na do Orinoco, foi a população do Madeira que contribui com maior número de indivíduos nessa faixa.

Morfologia. A análise populacional de $R$. affinis mostrou diferenças na morfologia do focinho. Pelo menos dois morfotipos puderam ser observados: (1) focinho com evidente heterognatismo (maxila superior adiante da inferior) e perfil superior reto; (2) focinho com pequeno heterognatismo e perfil superior levemente convexo, com tendência a reto. Tais diferenças só ficam mais claras se comparados exemplares de mesmo tamanho. Exemplares com o padrão 2 foram raros e, ocorreram em maior número, na drenagem do rio Madeira. Ambos os padrões estiveram presentes em exemplares da mesma região, MUSM 338, com tipo 1 e MUSM 1674 com tipo 2 - ambos de Pucallpa, alto rio Solimões (Figs. 1A, B) ou do mesmo local, MZUSP 34705 do rio Madeira (Figs. 1C, D) e MUSM 7840 do sistema do rio Madre de Dios. A associação, embora rara, da ocorrência desses morfotipos com a variação de outros caracteres (veja comentários mais abaixo) supõem que as diferenças na morfologia do focinho de $R$. affinis possuem causa distinta daquela comentada para $R$. descalvadensis (veja texto em Variação geográfica dessa espécie).

A análise conjunta da morfologia e das contagens mostrou que dois morfotipos em $R$. affinis puderam ser identificados, embora com ampla sobreposição nas proporções e nos limites das contagens: (1) corpo relativamente baixo, focinho longo, heterognatismo evidente em adultos, com a maxila superior bem mais adiante em relação a maxila inferior e a média do número de escamas pouco mais elevada (mais evidente no número de escamas perfuradas da linha lateral; (2) corpo relativamente mais alto, focinho mais curto, heterognatismo pouco acentuado em adultos, com a maxila superior pouco adiante da maxila inferior e a média do número de escamas perfuradas da linha lateral mais baixa. Tais morfotipos foram mais fáceis de identificar quando analisada a população da drenagem do rio Madeira. No entanto, ambos os morfotipos, em uma análise mais ampla, mostraram sobreposições na morfologia e nas contagens e não apresentam padrão geográfico claro, portanto, não sendo suficientemente

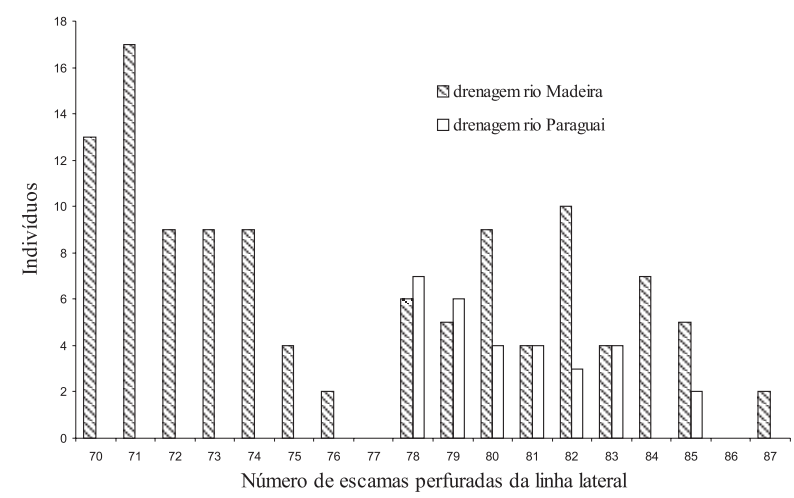

Fig. 10. Freqüência do número de escamas perfuradas da linha lateral entre as populações das drenagens do rio Madeira $(n=115)$ e do rio Paraguai $(\mathrm{n}=30)$ de Roeboides affinis. consistentes. Diante desse fato, mesmo considerando a limitação inerente dos caracteres utilizados na análise, não acho recomendável, no momento, considerá-las diferentes entidades taxonômicas, mantendo todas as populações sob um só nome, $R$. affinis.

Comentários. Anacyrtus affinis Günther, 1868 foi descrita a partir de dois exemplares coletados em Huallaga, Peru. Tanto a descrição original quanto os dados merísticos fornecidos mostram que Günther se baseou em um deles para a descrição da espécie. A contagem das escamas perfuradas da linha lateral dada por Günther confere com a do exemplar BMNH. 1867.6.13.62 (CP $83,6 \mathrm{~mm}$ ), embora algumas escamas estejam faltando (aprox. 80 escamas). O outro exemplar BMNH. 1867.6.13.61 (CP 74,4mm), com aproximadamente 70 escamas perfuradas, fica sendo paralectótipo.

$\mathrm{O}$ exame direto dos síntipos de $R$. affinis e do holótipo de $R$. bicornis confirmou a sinonímia desse último nome em relação ao primeiro.

Roeboides prognathus (Boulenger, 1895) foi descrita a partir de um exemplar coletado no sistema do rio Paraguai. Muito embora a diagnose apresentada em BOULENGER (1896) não contenha caracteres diagnósticos, contagens feitas a partir da fotografia do holótipo (BMNH 1895.5.17.238) e a respectiva figura apresentada no mesmo artigo (prancha 8, figura 4) mostram que o exemplar não pertence às outras duas espécies que habitam a drenagem do rio Paraguai, $R$. microlepis e $R$. descalvadensis. Diante dos valores aproximados das contagens de escamas realizada no holótipo - 79 escamas perfuradas da linha lateral, 18 escamas acima da linha lateral e 17 escamas abaixo da linha lateral - e da ampla variação encontrada no número de escamas das populações de $R$. affinis, que não a do Paraná-Paraguai (veja texto acima), faltam diferenças consistentes que justifiquem a manutenção da população do Paraguai com nome distinto do restante das populações analisadas. A partir disso, foi aqui decidido sinonimizar R. prognathus à $R$. affinis.

Roeboides thurni foi descrita da Guiana por EIGENMANN (1912: 399) sem qualquer comentário diagnóstico. A partir de então a espécie não foi mais citada, salvo em catálogos de tipos (HenN, 1928; IBARRA \& STEWART, 1987) ou em lista de espécies (HARDMAN et al., 2002; LuCEnA \& Menezes, 2003). A análise comparativa de lotes provenientes dos rios da Guiana e da drenagem do rio Suriname (não é registrada ocorrência de Roeboides a leste desta drenagem, incluindo a bacia do rio Maroni) com exemplares da região do alto rio Amazonas de onde foram descritas $R$. affinis e $R$. bicornis, associadas aos dados de um dos parátipos, MCZ 29943 (CP 63,0 mm), não mostrou diferenças que justificassem a manutenção de $R$. thurni como válida. Em consequência, essa espécie é aqui sinonimizada à $R$. affinis.

\section{Roeboides biserialis (Garman, 1890) (Fig. 11A)}

Cynopotamus biserialis, GARMAN (1890: 14). (Localidade-tipo: lago do Máximo, Amazonas, Brasil, restringida aqui a partir da designação do lectótipo).

Evermannella biserialis, EIGENMANN (1903: 146) (novo gênero).

Eucynopomus biserialis, Fowler (1904: 119) (nome de substituição a Evermannella, pré-ocupado em peixes). 
Evermannolus biserialis, Eigenmann in Eigenmann \& Ogle (1907: 8) (nome de substituição a Evermannella, pré-ocupado em peixes, porém sinônimo objetivo de Eucynopotamus). Roeboides biserialis, LuCENA (2000b: 155) (citação).

Material examinado. Sintipos: BRASIL, Amazonas: lectótipo, por presente designação: MCZ 21335, CP 43,0mm, lago do Máximo, [pequeno lago próximo a Parintins]. Paralectótipos, por presente designação: Vila Bela, [rio Amazonas em Parintins e arredores], MCZ 21327 (4 de 9, CP 42 - 47mm); lago do Máximo, [pequeno lago próximo a Parintins], MCZ 165930 (11 de 39, CP 33,5 - 44,6mm); Pará: Óbidos, [rio Amazonas], MCZ 21360 (10 de 24, CP 37 - 48mm). BRASIL, Amazonas: lagoa Janauari, 03 13 'S, 60 $1^{\prime}$ W, MCP 27980 (9 de 20, CP 51,6 - 40,0mm); paraná de Janauacá, entrada do lago Castanho, MZUSP não numerado PB 33 (CP 50,1 mm d\&c); Camaleão, ilha de Marchantaria, MZUSP não numerado PB 353 (CP 35,2mm); paraná de Janauacá, entrada do lago Castanho, MZUSP não numerado PB 531 (CP 49,3mm d\&c); lago Puraquequara, margem esquerda do rio Amazonas, MZUSP 88001 (CP 34,2mm); Rondônia: igarapé Bananeiras, Guajará-Mirim, 10³8'28"S, 65'17'34"W, MCP 37793 (CP 33,2mm). BOLIVIA, Beni: rio San Martin, drenagem do rio Mamoré, $13^{\circ} 20^{\prime} 17^{\prime \prime}$, $63^{\circ} 27^{\prime} 26^{\prime}$ 'W, UMSS 0220 (11, CP 48,5 - 60,0mm, 1CP CP $55,6 \mathrm{~mm}$ d\&c).

Diagnose. Difere das demais espécies do grupoaffins por apresentar duas séries de dentes no dentário (Fig. 12), versus uma única e não possuir os dentes D4 e D5 no dentário. De $R$. descalvadensis, que assemelha-se pela forma geral do corpo, difere pelo reduzido número de escamas da linha lateral, 58 a $64(n=26, m=59,5)$ (versus a 60 a $71, n=164, m=66,0)$.

Descrição. Dados morfométricos na Tabela I. Corpo alto. Perfil dorsal elevado a partir da base do processo supra-occipital até a origem da nadadeira dorsal, leve declive ao longo da base desta nadadeira, continuandose reto até o pedúnculo caudal. Perfil ventral convexo até a origem na nadadeira anal, reto deste ponto até o pedúnculo caudal. Boca terminal.

Focinho com perfil superior convexo, isognato. Maxilar longo, extremidade posterior atingindo a vertical que passa pelo meio da órbita, com nove a 14 [14] dentes cônicos de base larga, mais ou menos alinhados; algumas vezes o quinto e sexto ou sétimo e oitavo dentes mais desenvolvidos que os demais e levemente deslocados para a superfície do osso. Pré-maxilar com duas fileiras de dentes mais ou menos alinhadas; a externa com cinco a oito dentes mamiliformes, dirigidos para baixo, exceto o último, ou os dois últimos, que podem estar dirigidos para fora; a interna com seis a oito dentes, sendo os três primeiros mamiliformes e mais desenvolvidos que os restantes; alguns exemplares do médio Amazonas, incluindo a série típica, apresentaram um leve deslocamento dos dentes, formando o padrão semelhante ao característico do gênero (dentes externos D1, D2 e D3). Não foram verificadas cúspides nos dentes do prémaxilar ou maxilar. Dentário com duas fileiras de dentes; a externa com quatro a seis dentes mamiliformes mais ou menos alinhados dirigidos para cima, sendo os dois, ou três, primeiros mais desenvolvidos que os demais; a interna com 11 a 14 dentes mais ou menos alinhados, sendo os três primeiros mamiliformes e mais desenvolvidos que os restantes. Dentes externos D4 e D5 ausentes. Em um exemplar (MCP 27980), dois dentes estão levemente deslocados da fileira externa, sendo o correspondente ao D4 voltado para cima e o correspondente ao D5 dirigido para cima e levemente para frente. Rastros branquiais, cinco a seis no ramo superior [cinco] $(\mathrm{n}=30$, média $=5,5)$, oito a 10 no inferior [nove] ( $\mathrm{n}=32$, média $=8,8)$.

Nadadeira dorsal, i+9 raios, sua origem na vertical que passa sobre ou levemente atrás da origem da nadadeira anal. Nadadeira peitoral, i+10 a 13 raios [12] $(\mathrm{n}=31$, média $=11,8)$, seu raio mais longo alcançando a origem da nadadeira anal. Nadadeira ventral, i+7 raios, seu raio mais longo ultrapassando a origem da nadadeira anal; machos com um, ou dois ganchos ósseos por segmento presentes na metade superior da borda interna do primeiro ao sexto raio ramificado. Nadadeira anal, iv$\mathrm{v}+40$ a 46 raios [iv+42] (n=32, média=43,0); machos com um ou dois ganchos por segmento presentes na borda interna do último raio não ramificado até, no máximo, o $12^{\circ}$ raio ramificado. Nadadeira caudal furcada com $i+17+i$ raios principais. Escamas da linha lateral, 56 a $64(n=26$, média =59,5); escamas abaixo da linha lateral, 10 a 18 [12] $(\mathrm{n}=27$, média $=11,6)$; escamas acima da linha lateral, 11 a 15 [11] $(n=20$, média=12,7); escamas ao redor do pedúnculo caudal, 17 a $19(\mathrm{n}=6$, média=17,8). Trinta e oito vértebras totais, sendo 15 pré-caudais e 21 a 23 caudais ( 3 exs. $d \& c)$.

Coloração em álcool. Corpo claro, com uma faixa prateada longitudinal desde a região imediatamente posterior ao canto superior do opérculo até o final do pedúnculo caudal. Margens distal do focinho, e da maxila inferior, escurecidas; exemplares do rio Mamoré com porção superior do focinho enegrecida. Mancha umeral, pequena, arredondada, localizada logo acima da região póstero-superior do pseudotímpano; mancha caudal, pequena, sobre o pedúnculo caudal, logo a frente da base dos raios medianos da nadadeira caudal. Nadadeiras claras; exemplares do rio Mamoré com as nadadeiras dorsal, anal, caudal e ventrais escurecidas.

Distribuição. Rio Mamoré, sistema do rio Madeira e médio rio Amazonas (Fig. 13).

Variação geográfica. A comparação entre as médias do número de escamas da linha lateral das populações do médio rio Amazonas e rio Mamoré mostrou diferença significativa, sendo menor na primeira $(n=16,56$ a 62 , $\mathrm{m}=57,9)$ versus $(\mathrm{n}=9,60$ a $64, \mathrm{~m}=62,0)$, embora com pequena sobreposição entre os valores extremos. O reduzido número de exemplares examinados impede maiores interpretações.

Três exemplares provenientes da drenagem do rio Xingu, MZUSP 63431 (CP 76,9 mm) e MZUSP 34712 (CP 46,4-52,9mm), apresentam os dentes do dentário aproximadamente em duas fileiras. No entanto, diferente de $R$. biserialis, dois exemplares apresentam o dente $\mathrm{D} 4$ e um outro, o maior exemplar, também o D5. Além disso, possuem 64 a 69 escamas. Em razão de tais caracteres sugerirem que trata-se de uma espécie distinta, não considerei essa drenagem na distribuição de $R$. biserialis. A identidade dos lotes acima referidos fica na dependência do exame de mais exemplares. 
Comentários. Cynopotamus biserialis foi descrita a partir de 78 exemplares coletados durante a expedição Thayer - 1865 e 1866 - no lago do Máximo e em "Villa Bella", ambas as localidades próximas ao atual município de Parintins, Amazonas, e em Óbidos, Pará (Higuchi, 1992). Apesar do elevado número de exemplares, a descrição e os dados merísticos sem variação fornecidos por Garman sugerem que ele se baseou somente em um exemplar. Se isso realmente ocorreu, não há pistas para identificá-lo. É aqui designado o exemplar MCZ 21335 , CP 43,0mm, como lectótipo. Em conseqüência, os demais lotes MCZ 165930, MCZ 21327, MCZ 21360 e USNM 120180 passam a ser paralectótipos.

\section{Roeboides descalvadensis Fowler, 1932} (Figs. 11B, C)

Roeboides descalvadensis Fowler (1932: 359) (Localidade-tipo: Descalvados, Mato Grosso, Brasil, sistema do rio Paraguai) Roeboides paranensis Pignalberi (1975: 151) (Localidade-tipo: isla Ñanganui, Corrientes, Argentina, sistema do rio Paraná, abaixo da foz do Iguaçu; tipos não vistos). Novo sinônimo.

Material examinado. Tipo. BRASIL, parátipo de $R$. descalvadensis: Mato Grosso: Descalvados, setembro de 1931, J.A.G. Rehn, ANSP 53719 (CP 36,7mm). PERU, Loreto: riacho acima da boca do rio Zapatilla, próximo a cidade de Yanashi, 034' 26"'S, 73¹4'50"W, INHS 99610 (2, CP 43,0 - 43,4mm). Cocha Trueno a $6 \mathrm{Km}$ de Jenaro Herrera, MNHG 2091.79-80 (3, CP 35,6 - 50,8mm). BRASIL, Acre: rio Tarauacá, Tarauacá, MZUSP 34719 (53, CP 25,0 - 55,0mm); rio Tarauacá, Tarauacá, MZUSP 87999 (CP 46,4 mm); rio Tarauacá, Tarauacá, MZUSP 88000 (CP 57,4mm); Amazonas: ilha de Marchantaria, rio Solimões, 03ำ14'S, 59 58'W, MCP 27992 (12, CP 28,2 - 46,3 $\mathrm{mm}$ ); praia Caborini, confluência dos rios Solimões e Japurá, Alvarães, 0309'34"S, 6446'35”W, MCP 30596 (17, CP 34,7 $57,2 \mathrm{~mm}$ ); rio Solimões, São João do Janauacá, INPA 16189 (CP $38,6 \mathrm{~mm}$ ); lago Castro, boca do rio Purus, MZUSP 6286 (22, CP $30,0-45,8 \mathrm{~mm}$ ); lago Supiá, em frente a Codajás, MZUSP 35694 (4, CP 25,0 - 31,2mm); rio Madeira, Calama, MZUSP 88005 (2, CP 46,2 - 47,5mm); rio Solimões, próximo a Fonte Boa, MZUSP 41073 (3, CP 32,1 - 39,7mm); paraná de Janauacá, entrada do lago do Castanho, MZUSP não numerados, PB 33 (6, CP 26,8 $42,3 \mathrm{~mm}$ ); entre o lago Murumuru e Paraná de Janauacá, Bayley 234 não numerados ( 3 , CP 41,0 - 47,6mm, 1 CP 41,0mm d\&c); Camaleão, ilha de Marchantaria, MZUSP não numerados, $\mathrm{PB}$ 292 (+50, CP 30,1 - 40,8mm, 12 CP 24,0 - 40mm d\&c); mesmos dados, MZUSP não numerados, PB 309 (7, CP 27,9 - 48,2mm); paraná de Janauacá, entrada do lago do Castanho, MZUSP não numerados, PB 315 (+50, CP 30,0 - 50,8mm, 4 CP 32,0 - 51,0mm d\&c); lago Terra Preta, Janauari, MZUSP não numerados, PB 322 (11, CP 30,1 - 45,6mm); Camaleão, ilha de Marchantaria, MZUSP não numerados, PB 330 (6, CP 30,0 - 39,7mm); ressaca da ilha Marchantaria, MZUSP não numerados, PB 333 (5, CP 32,2 - 50,0mm); paraná de Janauacá, entrada do lago do Castanho, MZUSP não numerados, PB 334 (14, CP 30,5 - 49,9mm); Camaleão, ilha de Marchantaria, MZUSP não numerados, PB 353 (3, CP 36,0 - 39,0mm); paraná de Janauacá, entrada do lago do Castanho, MZUSP (Bayley 357) não numerados (10, CP 36,6 - 45,9mm); mesmos dados, MZUSP não numerados, PB 386 (9, CP 34,7 - 50,0mm); Camaleão, ilha de Marchantaria, MZUSP não numerados, PB 407 (11, CP 30,6 - 55,1mm); paraná de Janauacá, entrada do lago do Castanho, MZUSP não numerados, PB 432 (10, CP 31,1 - 49,9mm); mesmos dados, MZUSP não numerados, PB 531 (7, CP 24,8 - 36,1mm); Pará: rio Paituna, em frente a Monte Alegre, bacia do rio Tapajós, $02^{\circ} 0$ '00"S, 54 5'0"'W, MCP 29304 (CP 49,0mm); rio Amazonas, comunidade de Guajará, 02 13 '48'S, 550'00"W, MCP 29308 (2, CP 35,7 43,4mm); Oriximiná, MZUSP 20207 (11, 41,2 - 55,8mm); Cahoeira do Arari, ilha de Marajó, MZUSP 5027 (30, CP 40,7 56,6mm); rio Arari, Cachoeira do Arari, ilha de Marajó, MZUSP 35693 (2, CP 34,1 - 35,0mm); Mato Grosso: poça sob ponte da
Transpantaneira, 70Km além de Poconé, MCP 10736 (CP $50,5 \mathrm{~mm}$ ); Ribeirão dos Flexas, na estrada Cuiabá/Caceres, $69 \mathrm{Km}$ a leste de Cáceres (afluente do rio Paraguai), Cáceres, MCP 15594 (CP 49,2mm); rio Paraguai e arredores, Cáceres, MCP 15710 (45, CP 39,6 - 48,5mm); rio Cuiabá na baia do Poço, Sto. Antônio Leverger, MCP 26067 (3, CP58,1 - 70,4mm); Porto Esperidião, rio Paraguai, MZUSP 28086 (11, CP 52,4 - 69,0mm); São Paulo: Represa Hidrelétrica de Rosana, rio Paranapanema, próximo a foz do córrego São Carlos, Teodoro Sampaio, MCP 26168 (19, CP 32,4 - 39,1mm). BOLIVIA, Beni: alagado a $3 \mathrm{Km}$ da Estacion Biológica de Beni na estrada para Santo Ignacio, rio Apere, INHS
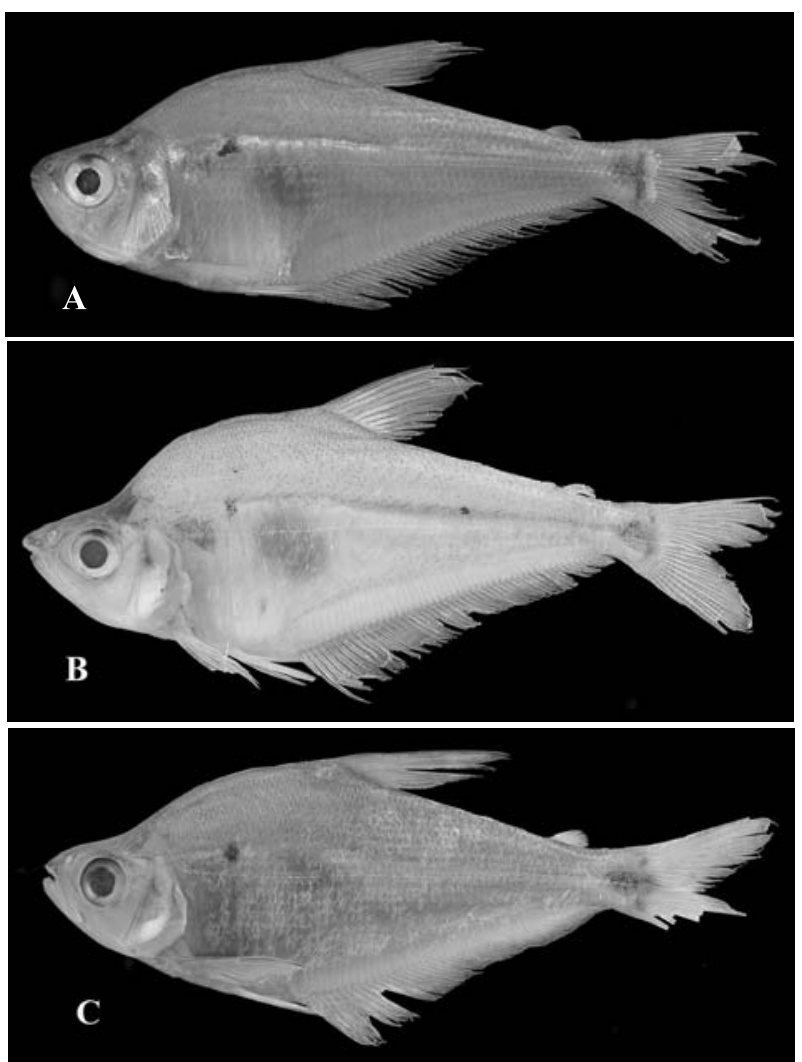

Fig. 11. A. Roeboides biserialis (Garman, 1890), MCP 27980, lago Janauari, rio Amazonas, Amazônia, CP 51,5mm, B. Roeboides descalvadensis Fowler, 1932, Porto Esperidião, rio Paraguai, MZUSP 28086, CP 67,9mm, C. Roeboides descalvadensis, lago Itaipu, Alto Paraguai, Paraguai, MHNG 2206.47, CP 66,1mm.

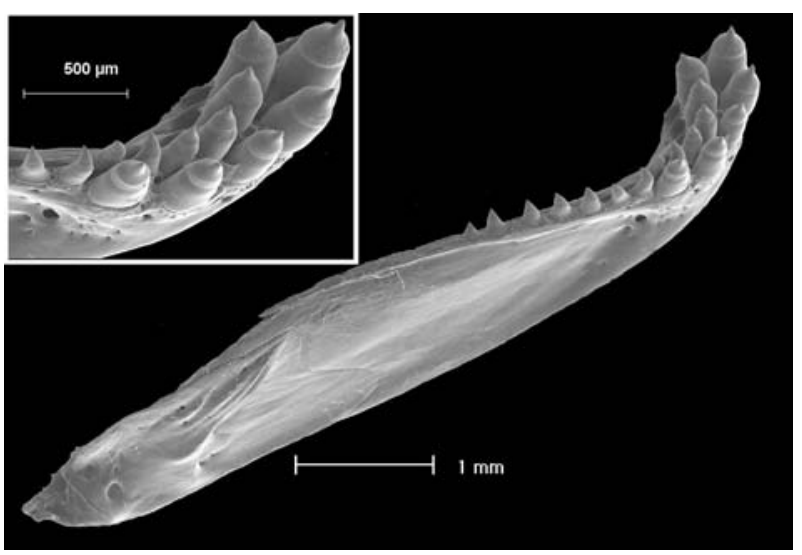

Fig. 12. Microscopia Eletônica de Varredura do dentário direito, vista lateral, de Roeboides biserialis (Garman, 1890), UMSS 0220, CP 55,6mm, rio San Martin, drenagem do rio Mamoré, Bolívia. A esquerda, detalhe da região anterior do dentário mostrando a disposição dos dentes. 
37101 (9, CP 42,6 - 63,7mm); rio Matos, Ballivia, $14^{\circ} 55^{\prime} \mathrm{S}$, $66^{\circ} 17^{\prime} \mathrm{W}$, MCP 18834 (2, CP 58,0mm; 1 CP 52,7mm d\&c); rio

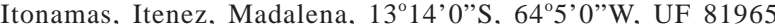
(4, CP 39,4-57,8mm); rio Ibare $5 \mathrm{Km}$ ao norte de Puerto Almacen, Cercado, $14^{\circ} 49^{\prime \prime S}, 64^{\circ} 58^{\prime} 0^{\prime \prime} \mathrm{W}, \mathrm{UF} 160277$ (2, CP 42,8 - 48,8mm); rio Popoi, bacia do rio Beni, UMMZ 66353 (2, CP 52,7 - 69,1mm); rio Matos, Ballivia, $14^{\circ} 55^{\prime} \mathrm{S}, 66^{\circ} 17^{\prime} \mathrm{W}$, USNM 305343 (65, CP $41,4-54,4 \mathrm{~mm})$; área alagada a $2,5 \mathrm{Km}$ a oeste do rio Matos, Ballivia, $14^{\circ} 55^{\prime} \mathrm{S}, 6^{\circ} 17^{\prime} \mathrm{W}$, USNM 323606 (45, CP 36,2 - 57,5mm); Cochabamba: rio Chaparé, Todos Santos, ANSP 180931 (CP 40,9mm); laguna Yuca, 6Km abaixo de Puerto Villaroel, 16 $46^{\prime} 38^{\prime \prime} \mathrm{S}, 64^{\circ} 47^{\prime} 49^{\prime \prime} \mathrm{W}, \mathrm{MCP} 35413$ (2, CP 44,5 $52,0 \mathrm{~mm})$; rio Chaparé, confluência com o rio Coni, acima de Todos los Santos, MZUSP 35948 (3, CP 38,5 - 39,8mm); lagoas ao longo do rio Ichilo, próximo a confluência com o rio Chapare, $64^{\circ} 36^{\prime} \mathrm{S}, 16^{\circ} 57^{\prime} \mathrm{W}$, UMSS 0217 (CP 58,7mm). PARAGUAI, Central: lago Ypacarai, Aregua, $25^{\circ} 20^{\prime} 00^{\prime} \mathrm{S}, 57^{\circ} 20^{\prime} 0^{\prime \prime} \mathrm{W}$, MNHNP 818 (2, CP 72,4 - 89,3mm); lago Ypacarai, aprox. a $200 \mathrm{~m}$ da terminal de linha Aregua, Aregua, $25^{\circ} 20^{\prime} 0^{\prime \prime} \mathrm{S}$, $57^{\circ} 20^{\prime} 00^{\prime \prime} \mathrm{W}$, MNHNP 822 (CP 80,0mm); arroio Yaguaresau cerca de $13,5 \mathrm{Km}$ de Caacupe, $25^{\circ} 22^{\prime} 42^{\prime}$ 'S, $57^{\circ} 15^{\prime} 18^{\prime}$ 'W, UMMZ 205954 (12, CP 49,1 - 61,4mm); Concepción: estância Laguna Negra, ca $1,5 \mathrm{Km}$ da sede, província, Paso Barreto, 233's, $57^{\circ} 01^{\prime} \mathrm{W}$, NRM 23189 (42, CP 38,3 - 68,9mm); mesmos dados NRM 23191 (79, CP 28,7 - 70,9mm); laguna conectado ao rio

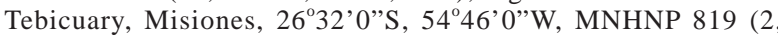
CP 73,6 - 74,7mm); Cordillera, lago Ypacarai, 6,3 Km a oeste de Centro Militar Naval e Aeronáutico, San Bernardino, MNHNP 791 (8, CP 43,1 - 64,9mm); Alto Paraná: Estação de Aqualcultura Itaipu Binacional, Hernandarias, MCP 18795 (2, CP 73,0 mm; CP 58,5mm d\&c); lago Itaipu, MHNG 2206.47 (20, CP 58,6 $85,0 \mathrm{~mm})$; Misiones: lagunas próximas a confluencia dos rios Tebicuary e Tebicuary-mi, Misiones, MNHNP 820 (4, CP 42,0 77,3mm); rio Tebicuary, Cento-Cué, NRM 33097 (20, CP 72,9 60,6 $\mathrm{mm}$ ); Presidente Hayes: Rota Trans-Chaco Km 194, arroio a $20 \mathrm{~m}$ da rota, MNHNP 790 (36, CP $32,7-66,8 \mathrm{~mm}$ ); rio Negro onde cruza a rota Trans-Chaco, MNHNP 817 (7, CP 51,9 $69,4 \mathrm{~mm}$ ); Estancia La Rural, 24 $50^{\circ} 4^{\prime \prime} \mathrm{S}, 57^{\circ} 46^{\prime} 24^{\prime \prime} \mathrm{W}, \mathrm{MHNP}$ 1382 (4, CP 57,4 - 60,5mm); Km 194 Transchaco, MNHNP 1060-1065 (6, CP 42,8 - 64,6mm); mesmos dados MNHNP 1065 (CP 64,6mm); Depto. Paraguarí, lago Ypoa, Paraguarí, $25^{\circ}$ $56^{\prime} \mathrm{S}, 57^{\circ} 26^{\prime} \mathrm{W}$, MNHNP 821 (CP 72,8 mm); Depto. Alto Paraguay, estância Dona Julia, Bahía Negra, 20¹0'57"S, $58^{\circ} 9^{\prime} 27^{\prime}$ 'W, MNHNP 1228 (CP 44,0mm); rio Montelindo, $23^{\circ} 56^{\prime} 42^{\prime \prime} \mathrm{S}, \quad 58^{\circ} 27^{\prime} 36^{\prime \prime} \mathrm{W}, \mathrm{UMMZ} 207241$ (8, CP 32,4 41,3mm). ARGENTINA, Buenos Aires: rio de La Plata, Punta Lara, MCP 10148 (48,8mm); Corrientes: rio Riachuelo, afluente do rio Paraná, MCP (6, CP 41,9-77,2mm; 2 CP 40,0 - 43,4mm d\&c); laguna Totora, San Cosme, 40Km de Corrientes, MZUSP 10251 (CP 56,6mm)

Diagnose. Roeboides descalvadensis distingue-se de $R$. affinis pelo reduzido número de escamas perfuradas da linha lateral 60 a $71(\mathrm{~m}=65,9)$, versus 69 a $87(\mathrm{~m}=75,6)$, acima da linha lateral, 12 a $16(\mathrm{~m}=14,6)$ versus 15 a 23 $(\mathrm{m}=18,3)$ e pelo menor comprimento do focinho em relação ao CP (Fig. 2). De R. numerosus e R. xenodon difere por apresentar 10 a 11 rastros no ramo inferior do primeiro arco branquial versus 12 a 14 na primeira e 7 a 8 na segunda. De $R$. oligistos pelo elevado número de raios ramificados da nadadeira anal, 42 a $52(\mathrm{~m}=47,1)$, versus 38 a $44(\mathrm{~m}=40,8)$, maior altura do corpo em relação ao CP, 34,3 a 45,4\% $(\mathrm{m}=38,9 \%)$, versus 29,4 a $38,7 \%(\mathrm{~m}=34,2 \%)$ e presença de manchas umeral e caudal, versus ambas ausentes. De Roeboides sazimai, que possui valores das contagens semelhantes, $R$. descalvadensis difere mais notadamente na forma geral do corpo, quando comparados exemplares de mesmo tamanho e acima de CP 60,0mm: focinho com perfil usualmente convexo e curto, $25,5 \%$ a $28,0 \%$ do comprimento da cabeça $(\mathrm{n}=5, \mathrm{~m}=26,6 \%)$ e com corpo mais alto, $38,1 \%$ a $43,3 \%$ do $\mathrm{CP}(\mathrm{n}=5, \mathrm{~m}=40,2 \%)$ (Fig. 14$)$, versus focinho com perfil reto e mais longo, $27,6 \%$ a $29,4 \%$ do comprimento da cabeça $(n=9, m=28,4 \%)$ e com corpo mais baixo, $34,8 \%$ a $39,2 \%$ do $\mathrm{CP}(\mathrm{n}=9, \mathrm{~m}=37,5 \%)$. Na Análise de Componentes Principais os dois valores mais significativos que influenciaram no Componente II $(3,12 \%$ da variância) para diferenciar essas duas espécies foram o comprimento do focinho e a altura do corpo (Fig. 15, Tab. IV).

Descrição. Dados morfométricos na Tabela V. Corpo alto. Perfil dorsal elevado a partir da base do processo supra-occipital até a origem da nadadeira dorsal, leve declive ao longo da base desta nadadeira, continuandose reto até o pedúnculo caudal. Perfil ventral convexo até a origem na nadadeira anal, reto a partir daí até o pedúnculo caudal. Boca terminal a subterminal.

Focinho com perfil superior convexo, reto em exemplares adultos acima de $80,0 \mathrm{~mm} \mathrm{CP}$, mas podendo ocorrer variação (veja abaixo), projetando-se pouco além da maxila inferior. Maxilar longo, extremidade posterior atingindo a vertical que passa no meio do olho, com seis a 15 dentes, os primeiros dois ou seis, cônicos, seguidos, nos adultos, de um ou dois dentes mamiliformes, desenvolvidos, deslocados para a superfície externa do osso; os restantes mamiliformes, ou cônicos de base

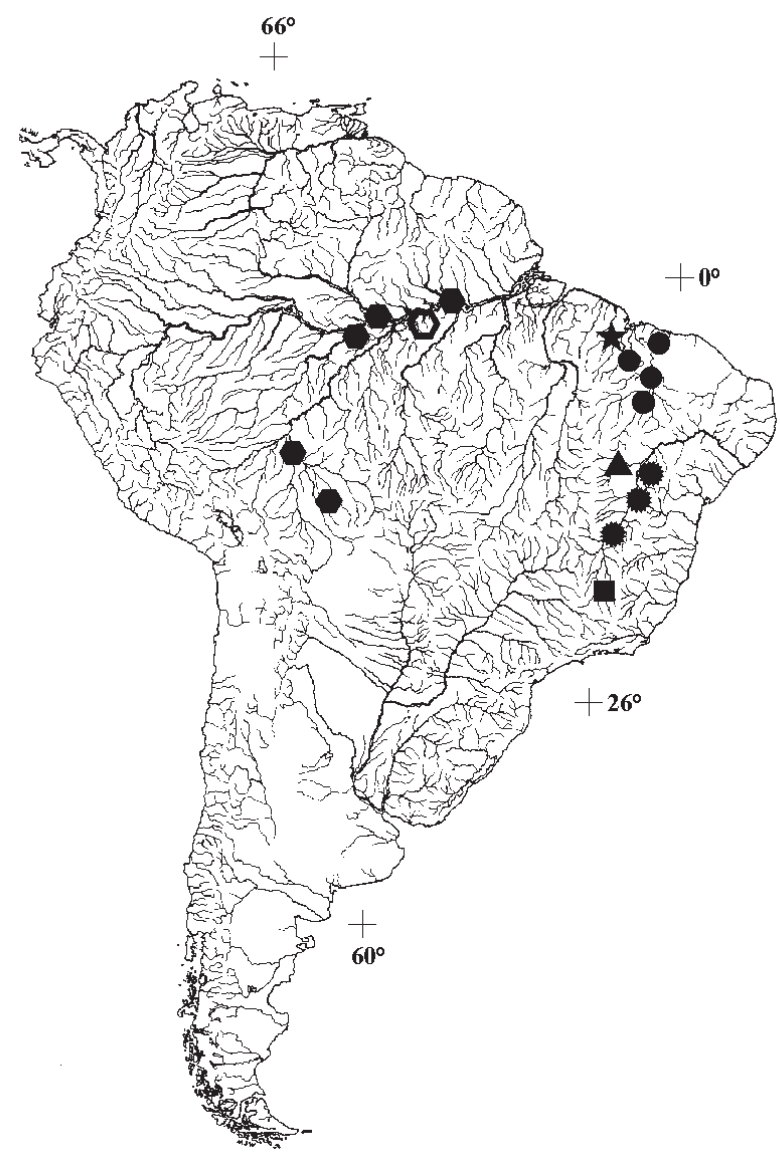

Fig. 13. Mapa com a distribuição de Roeboides biserialis (losango branco, localidade-tipo), $R$. sazimai (estrela, localidade-tipo) e $R$. xenodon (quadrado, localidade-tipo). Triângulo, localidade-tipo de $R$. francisci. Um sinal pode indicar mais de um local de coleta e/ou exemplares. 
larga, localizados na borda do osso. Pré-maxilar com três dentes mamiliformes externos sem cúspides: um, anterior, desenvolvido, e dirigido para frente (corresponde ao dente D1 em LuCENA, 1998), outro localizado no ramo lateral e dirigido para fora (corresponde ao dente D2 em LuCENA, 1998), e o terceiro, acima do dente D2, dirigido para frente e para fora (correspondente ao dente D3 em LuCEnA, 1998); D2 e D3 menores que o D1. Mais internamente, os dentes não possuem arranjo ou número definidos, diferindo, inclusive, de um pré-maxilar para outro; na disposição mais constante ocorre uma fileira com quatro a seis dentes mamiliformes, desalinhados, que acompanha a borda interna do pré-maxilar, o terceiro, ou quarto dente, mais desenvolvido e dirigido para frente; a seguir há dois dentes mamiliformes, posicionados próximos à junção entre os dois pré-maxilares, seguindose um hiato e, na porção final do ramo lateral do prémaxilar, uma fileira de três a cinco dentes cônicos pequenos. Dentário com dois dentes mamiliformes externos sem cúspides, um anterior dirigido para frente (correspondente ao dente D4 em LuCENA, 1998) e outro em posição lateral, e num plano mais inferior em relação ao D4, dirigido para fora (corresponde ao dente D5 em LUCENA, 1998); margem do dentário com um dente sinfiseal mamiliforme, grande, seguido de quatro a seis dentes cônicos ou mamiliformes pequenos e um mamiliforme grande, geralmente dirigido para fora, e uma série lateral de seis a 11 pequenos dentes cônicos, de base larga. Em alguns exemplares adultos, acima de $75 \mathrm{~mm} \mathrm{CP}$, podem ocorrer dois ou três dentes pequenos externos à série anterior de dentes. Dentes sinfiseanos com duas pequenas cúspides, raramente uma, localizadas na região póstero-superior do dente. Rastros branquiais, seis a nove no ramo superior [sete] $(\mathrm{n}=187$, média=6,8), 10 a 11 no inferior [11] ( $\mathrm{n}=186$, média=10,4).

Nadadeira dorsal, i+9 raios, sua origem na vertical que passa levemente atrás da origem da nadadeira anal. Nadadeira peitoral, $i+11$ a 14 raios [12] $(n=177$, média=12,2), seu raio mais longo alcançando ou não a origem da nadadeira anal. Exemplares até 22,4 mm CP com a nadadeira peitoral na forma larval. Nadadeira ventral,

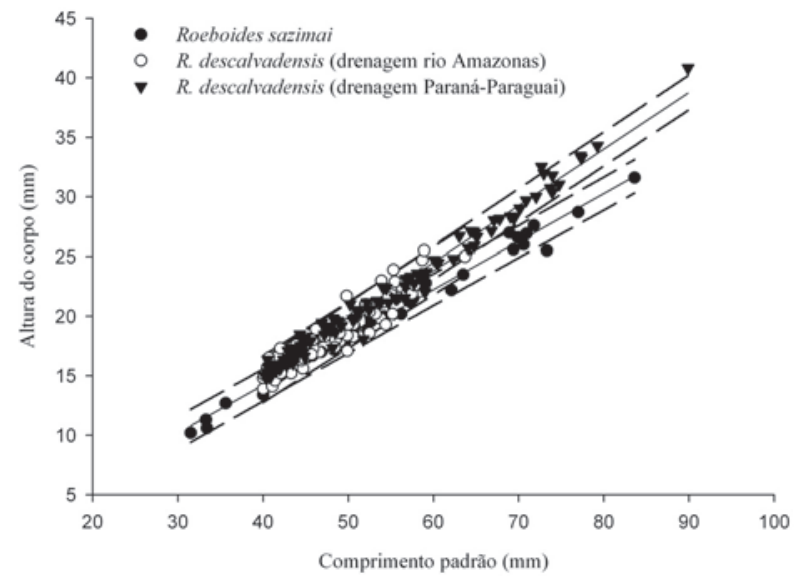

Fig. 14. Regressões da altura do corpo em relação ao comprimento padrão em Roeboides descalvadensis e $R$. sazimai. Linhas tracejadas representam os intervalos de confiança de $95 \%$. i+7 raios, seu raio mais longo ultrapassando a origem da nadadeira anal; machos com um ou dois ganchos ósseos por segmento presentes na metade superior da borda interna do primeiro ao quinto raio ramificado. Nadadeira anal, iv-v+42 a 52 raios [50] $(\mathrm{n}=186$, média=47,2); machos com um ou, mais raramente, com dois ganchos por segmento presentes na borda interna do último raio não ramificado até, no máximo, o $15^{\circ}$ raio ramificado. Nadadeira caudal furcada com $\mathrm{i}+17+\mathrm{i}$ raios principais. Escamas da linha lateral, 60 a 71 [70] $(n=164$, média=65,9); escamas abaixo da linha lateral, 11 a 15 [13] $(n=175$, média=13,5); escamas acima da linha lateral, 12 a $16 \quad(n=143$, média $=14,7)$; escamas ao redor do pedúnculo caudal, 15 a 20 [17] $(n=138$, média=17,6). Trinta e cinco a 38 vértebras totais, sendo 14 ou 15 pré-caudais [15] e 21 a 24 caudais [22], em 18 exemplares d\&c.

Coloração em álcool. Corpo claro, com uma larga faixa prateada longitudinal, desde a região imediatamente

Tabela IV. Escores individuais nos três primeiros eixos canônicos para as medidas em $R$. descalvadensis $(\mathrm{n}=78)$ e R. sazimai $(\mathrm{n}=34)$. Os dois valores mais altos em negrito.

\begin{tabular}{lccc}
\hline Medidas & Componente I & Componente II Componente III \\
\hline Compr. padrão & 0,2707 & 0,1449 & $-0,0791$ \\
Altura do corpo & 0,3095 & $\mathbf{0 , 4 0 6 3}$ & $-0,0192$ \\
Compr. pré-dorsal & 0,2701 & 0,2222 & $-0,0428$ \\
Compr. pré-anal & 0,2927 & 0,1863 & $-0,09147$ \\
Compr. pré-peitoral & 0,2582 & 0,04769 & $-0,04161$ \\
Compr. pré-ventral & 0,2712 & 0,1477 & $-0,06937$ \\
Compr. ped. caudal & 0,2896 & $-0,2302$ & $\mathbf{- 0 , 5 8 8 8}$ \\
Altura ped. caudal & 0,3224 & $-0,01179$ & 0,2749 \\
Compr. cabeça & 0,2466 & 0,02498 & $-0,02469$ \\
Compr. focinho & 0,3017 & $\mathbf{- 0 , 7 6 0 1}$ & 0,09114 \\
Diâmetro órbita & 0,188 & 0,1439 & $-0,1397$ \\
Compr. maxilar & 0,2556 & $-0,2305$ & $-0,1333$ \\
Espaço interorbital & 0,303 & $-0,02102$ & $\mathbf{0 , 7 1 2 9}$ \\
Eigenvalue & 0,6879 & 0,0229 & 0,0054 \\
Variância & $93,7 \%$ & $3,12 \%$ & $0,745 \%$ \\
\hline
\end{tabular}

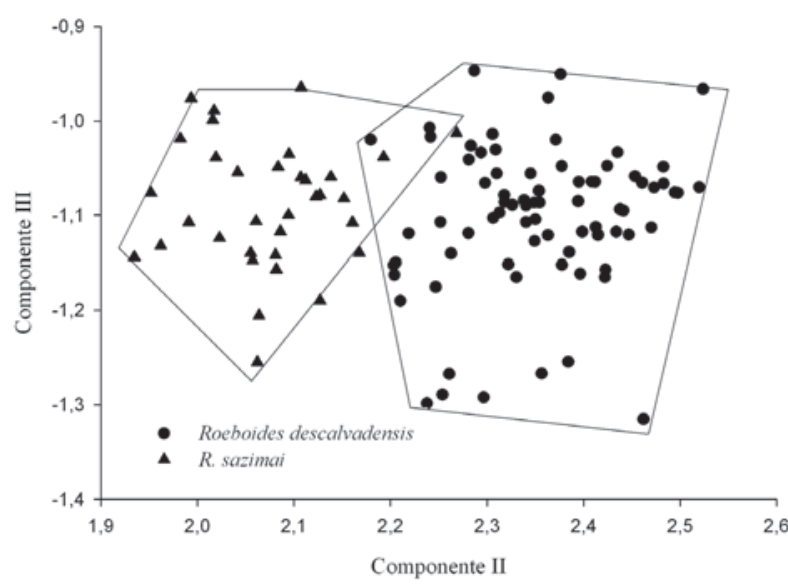

Fig. 15. Plotagem dos escores dos componentes principais II e III das treze medidas de Roeboides descalvadensis e $R$. sazimai sp. nov. 
posterior a borda superior do opérculo até o final do pedúnculo caudal; algumas vezes, ao invés desta faixa, há uma linha escura longitudinal desde a região imediatamente posterior ao pseudotímpano até o final do pedúnculo caudal. Margem distal do focinho escurecida; margem distal da maxila inferior podendo estar escurecida em alguns exemplares. Mancha umeral pequena, às vezes reduzida a poucos cromatóforos, localizada na região póstero-superior do pseudotímpano; mancha sobre o pedúnculo caudal grande e conspícua, larga na base dos raios da nadadeira caudal e afilando-se para frente. Ambas as manchas podem ou muito apagadas ou mesmo ausentes. Nadadeiras hialinas.

Distribuição. Amplamente distribuída nas bacias do rios Paraná, Paraguai e Amazonas (Fig. 16).

Variação geográfica. A análise comparativa entre as populações amazônica e Paraná-Paraguai mostrou alguma diferença no comprimento do focinho, quando comparados exemplares entre 50 e $60 \mathrm{~mm}$ CP (Fig. 2). Também foi verificado que a população de ilha do Marajó (MZUSP 5027) possui o diâmetro da órbita maior (31,9 a $36,2 \%, \mathrm{n}=15, \mathrm{~m}=33,6 \%$ ) quando comparados com o restante da população da espécie considerando exemplares maiores que $67,0 \mathrm{~mm}(26,8$ a $31,7 \%, \mathrm{n}=17$, $\mathrm{m}=28,7 \%$ ).

Digno de registro é a variação na morfologia do focinho observada em exemplares acima de $64,0 \mathrm{~mm} \mathrm{CP}$ da população Paraná-Paraguai. Dois morfotipos puderam ser identificados: (1) focinho longo, com perfil reto e heterogatismo evidente (MZUSP 28086) (Fig. 11B) e (2) focinho curto, com perfil convexo e heterognatismo pouco evidente (MHNG 2206.47) (Fig. 11C).

Estudos tem demonstrado que o desenvolvimento das maxilas em Roeboides tem relação com o hábito lepidofágico (Sazima \& Machado, 1982; Peterson \&
McInTYRe, 1998; NovaKowsKi et al., 2004), sendo que as espécies heterognatas típicas teriam maior habilidade na captura de escamas. Ou seja, essas seriam mais especialistas na captura de escamas. NovaKowski et al. (2004) ao estudarem sobre a variação ontogenética da dieta e o desenvolvimento dentário de $R$. descalvadensis $(R$. paranensis daqueles autores) concluíram que o consumo de escamas aumentou de $7 \%$ para $40 \%$ a medida em que os dentes migravam para fora da boca tornandose mais resistentes. Na medida que foi verificado aqui que exemplares de aproximadamente mesmo tamanho, portanto teoricamente com o mesmo grau de desenvolvimento da maxila superior e dos dentes, apresentam condições distintas, um do outro, nesses caracteres, pode-se conjecturar que o grau de especialismo pode variar também intraespecificamente, embora em grau bem menor que entre as espécies. Como hipótese a ser futuramente testada, a variação intraespecifica na população do Paraguai-Paraná de $R$. descalvadensis, poderia estar relacionada ao ambiente e a disponibilidade de alimento. No caso dos exemplares com focinho curto, perfil convexo e com dentes externos, comparativamente pouco desenvolvidos, o ambiente poderia ter proporcionado alta disponibilidade do alimento preferencial (insetos e microcrustáceos segundo Novakowski et al., 2004) e, ao mesmo tempo, haver reduzido número de espécie(s)-presa(s) utilizada(s) para a captura de escamas. Por outro lado, os exemplares do lote MZUSP 28086 com focinho longo, perfil reto, e com dentes externos comparativamente, robustos, poderiam ter reduzido o seu alimento preferencial e, ao mesmo tempo, teria ocorrido maior disponibilidade de espécie(s)presa(s) para a captura de escamas.

Roeboides descalvadensis possui ampla distribuição nas bacias Amazônica e Paraná-Paraguai o que poderia indicar variações amplas na morfologia e contagens. Afora os comentários sobre o diâmetro da

Tabela V. Dados morfométricos de $R$. descalvadensis considerando as drenagens individualizadas (A, holótipo 53718; B, parátipo, ANSP 53719; m, média; n, número de exemplares, não incluindo o holótipo e parátipo; SD, desvio padrão).

\begin{tabular}{|c|c|c|c|c|c|c|c|c|c|c|c|c|}
\hline \multirow[b]{3}{*}{ Medida } & \multirow{2}{*}{\multicolumn{6}{|c|}{$\begin{array}{l}\text { Amazonas } \\
\text { Limites }\end{array}$}} & \multirow{2}{*}{\multicolumn{6}{|c|}{$\begin{array}{c}\text { Paraná-Paraguai } \\
\text { Limites } \\
\end{array}$}} \\
\hline & & & & & & & & & & & & \\
\hline & & B & $\mathrm{n}$ & Min & Máx & $\mathrm{m}$ & \multirow[t]{2}{*}{ SD } & \multirow{2}{*}{$\frac{\mathrm{n}}{111}$} & \multirow{2}{*}{$\frac{\text { Min }}{40,2}$} & \multirow{2}{*}{$\begin{array}{l}\text { Máx } \\
89,9\end{array}$} & \multirow{2}{*}{$\frac{\mathrm{m}}{54,0}$} & \multirow[t]{2}{*}{ SD } \\
\hline Compr. padrão (mm) & 36,7 & 36,7 & 83 & 40,0 & 63,7 & & & & & & & \\
\hline \multicolumn{13}{|c|}{ Porcentagens do comprimento padrão } \\
\hline Altura do corpo & 37,0 & 33,8 & 81 & 34,3 & 43,6 & 38,2 & 2,084 & 110 & 34,9 & 45,4 & 39,7 & 1,865 \\
\hline Compr. pré-dorsal & 50,9 & 51,5 & 83 & 50,1 & 55,4 & 52,4 & 1,229 & 111 & 49,7 & 54,3 & 52,0 & 0,929 \\
\hline Compr. pré-anal & 46,6 & 47,9 & 82 & 44,6 & 51,6 & 47,7 & 1,703 & 111 & 44,1 & 54,2 & 47,2 & 1,596 \\
\hline Compr. pré-peitoral & & 30,5 & 83 & 24,3 & 29,9 & 27,6 & 1,162 & 110 & 24,4 & 29,1 & 26,5 & 0,903 \\
\hline Compr. pré-ventral & & 39,8 & 83 & 32,6 & 40,0 & 36,4 & 1,388 & 111 & 33,8 & 38,8 & 35,9 & 0,867 \\
\hline Compr. ped. caudal & & 8,7 & 69 & 6,5 & 10,0 & 8,0 & 0,832 & 111 & 6,6 & 9,5 & 8,2 & 0,569 \\
\hline Altura ped. caudal & & 7,2 & 83 & 5,8 & 9,4 & 8,1 & 0,711 & 111 & 6,6 & 9,4 & 7,9 & 0,537 \\
\hline Compr. cabeça & 28,9 & 27,2 & 83 & 24,5 & 28,9 & 26,8 & 0,915 & 111 & 24,0 & 27,6 & 25,9 & 0,871 \\
\hline \multicolumn{13}{|c|}{ Porcentagens do comprimento da cabeça } \\
\hline Compr. focinho & 25,5 & 23,0 & 76 & 21,2 & 28,8 & 25,0 & 1,667 & 110 & 21,9 & 27,1 & 22,3 & 1,929 \\
\hline Diâmetro órbita & 30,2 & 42,0 & 74 & 28,2 & 38,8 & 34,1 & 2,314 & 111 & 26,8 & 36,8 & 32,0 & 2,321 \\
\hline Compr. maxila & & 44,0 & 83 & 37,7 & 50,4 & 45,7 & 2,699 & 110 & 40,8 & 52,2 & 47,0 & 1,859 \\
\hline Espaço inter-orbital & & 27,0 & 83 & 20,2 & 29,3 & 26,1 & 1,791 & 110 & 19,8 & 30,3 & 26,8 & 2,175 \\
\hline
\end{tabular}


órbita, e comprimento e forma do focinho, feitos acima, foram verificadas variações em alguns lotes, que por serem provenientes de uma área limitada da distribuição da espécie, merecem registro. O exame de exemplares provenientes da drenagem do rio Madre de Dios, Peru (ANSP 143573, ANSP 143572, USNM 270256, USNM 317788 e USNM 319652), mostrou variação de nove a 10 rastros no ramo inferior do primeiro arco branquial (13 exemplares com nove rastros e dois com 10) ao contrário do restante do material examinado, que apresentou de 10 a 11 rastros. Além disso, alguns exemplares mostraram focinho curto, excessivamente abrupto e com perfil convexo. Embora o formato do focinho tenha variado na espécie (veja texto acima), o fato desta população apresentar nove rastros, levou a não inclusão destes na distribuição da espécie. Também não foram incluídos o lote da mesma drenagem, MUSM 8832, lago Valencia, Tambopata. Os exemplares apresentam focinho curto e convexo, porém menos abrupto quando comparados com os lotes citados anteriormente, e diferem destes ainda, e dos demais examinados, pelo elevado número de escamas da linha lateral ( 70 a $74, n=18, m=72$ versus 60 a $71, n=164$, média $=65,9$ ). Todos esses lotes diferem de forma inequívoca de $R$. affinis, espécie que ocorre na mesma drenagem, pela morfologia do focinho e altura do corpo. Muito provavelmente os lotes citados pertençam a duas espécies distintas, o que, no entanto, só poderá ser confirmado com o exame adicional de exemplares.

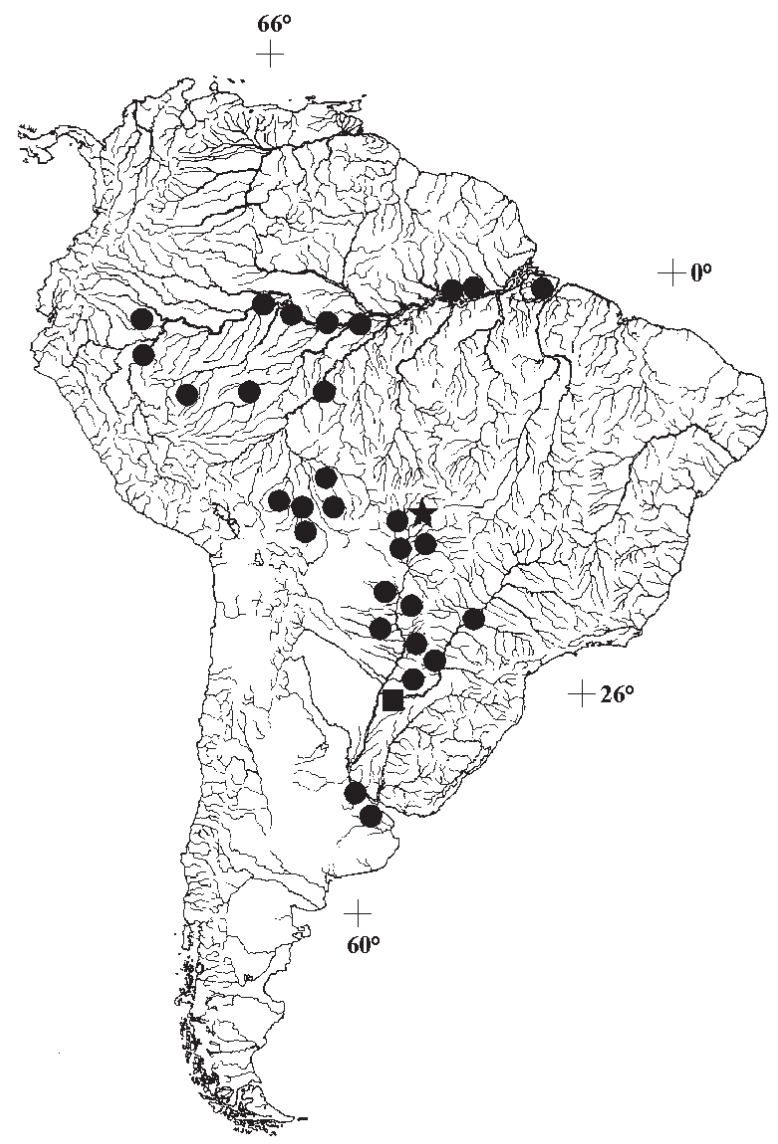

Fig. 16. Mapa com a distribuição de Roeboides descalvadensis (estrela, localidade-tipo). Quadrado, localidade-tipo de R. paranensis. Um sinal pode indicar mais de um local de coleta e/ou exemplares.
Comentários. Roeboides descalvadensis foi descrita por Fowler (1932) a partir de dois exemplares coletados em Descalvados, localidade às margens do rio Pargauai no pantanal matogrossense, Brasil. Na descrição da espécie o autor apresenta a variação de 53 a 55 escamas perfuradas na linha lateral até a base da [nadadeira] caudal, com "3 more on latter". Pignalberi (1975), ao descrever R.paranensis, fornece como principal diferença de $R$. descalvadensis o maior número de escamas perfuradas na linha lateral da primeira, 66 a 71 versus 56. Posteriormente, LuCENA (1988) difere ambas espécies baseando-se no número de escamas perfuradas na linha lateral e no contorno superior do focinho, mais convexo em $R$. descalvadensis. O exame de um parátipo de $R$. descalvadensis (ANSP 53719) e os dados do holótipo ANSP 53718 (fornecidos à época por William Saul) mostraram que este possui 66 escamas perfuradas na linha lateral enquanto o parátipo, 70 escamas. Ambos, portanto, dentro dos limites dados por Pignalberi para $R$. paranensis. A análise de uma série maior de exemplares, e de várias classes etárias, indicou que o contorno superior do focinho é um caráter extremamente variável dentro da espécie. Tanto em exemplares jovens quanto em adultos ocorrem perfis retos e convexos; foi verificado uma tendência de os machos, evidenciados pela presença de ganchos na nadadeira anal, apresentarem um perfil mais acentuadamente convexo, entretanto, isso não foi uma ocorrência constante. Tendo em vista a variação no

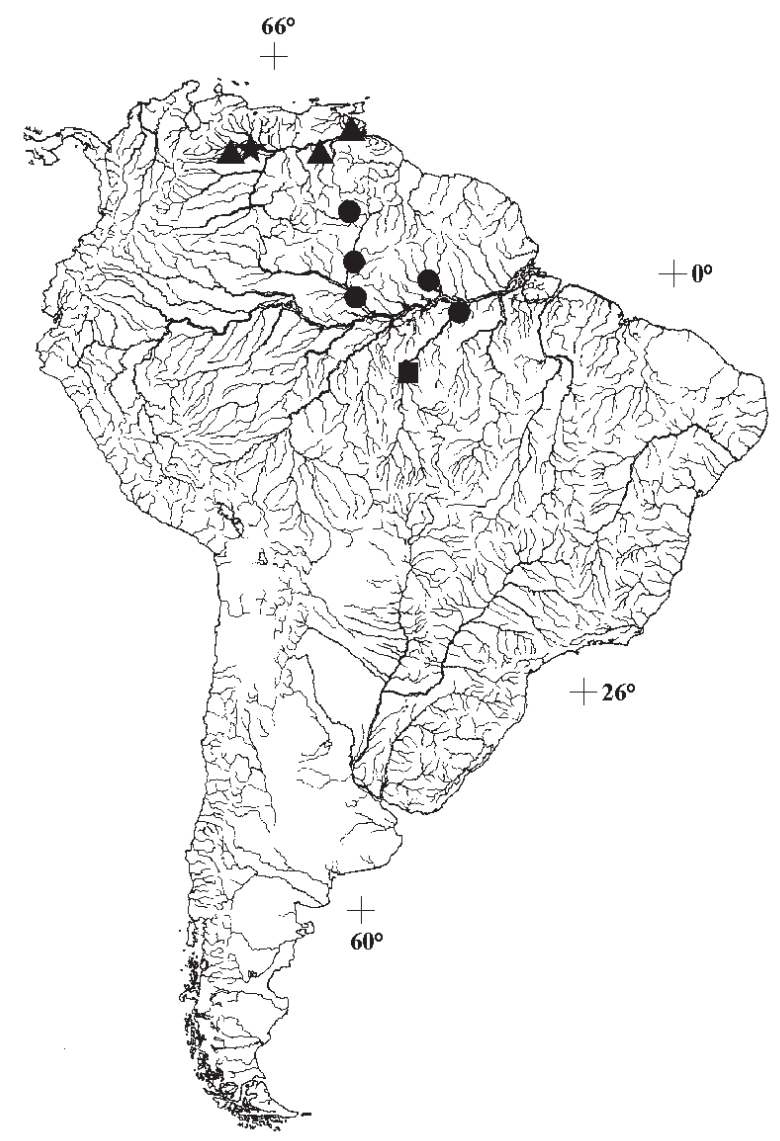

Fig. 17. Mapa com a distribuição de Roeboides numerosus (estrela, localidade-tipo) e $R$. oligistos (quadrado, localidade-tipo). Um sinal pode indicar mais de um local de coleta e/ou exemplares. 
contorno superior do focinho, o número de escamas da linha lateral não representar um caráter diagnóstico, e nenhuma característica diferencial ter sido encontrada no exaustivo exame das populações examinadas, concluo que $R$. paranensis deve ser considerado um sinônimo júnior de $R$. descalvadensis.

\section{Roeboides numerosus Lucena, 2000}

Roeboides numerosus LuCENA (2000b:154) (Localidade-tipo: arroio na estrada San Fernando de Apure-Arichuma, drenagem do rio Apure, sistema do rio Orinoco).

Material adicional examinado. VENEZUELA, Delta Amacuro: Caño Guarguapo, cerca de 500 metros da boca com o rio Orinoco, MCP 26494 (3, CP 42,4 - 49,6mm; 1 CP 49,4mm d\&c); Guarico: rio Apure, MCP 26495 (3, CP 42,1 - 51,7mm).

Diagnose. Roeboides numerosus difere de todas as demais espécies do grupo-affinis pelo elevado número de rastros no ramo inferior do primeiro arco branquial, 12 a 14 versus 7 a 11 .

Distribuição. Bacia do rio Orinoco.

\section{Roeboides oligistos Lucena, 2000}

Roeboides oligistos LuCENA (2000b: 157) (Localidade-tipo: braço morto do rio Tapajós, Itaituba, sistema do rio Amazonas).

Material adicional examinado. BRASIL, Amazonas: rio Branco abaixo de Virua, $01^{\circ} 16$ '44"S, 61 50 '32"W, MZUSP 87998 (2, CP 41,9 - 50,0mm); rio Jauaperi, Jauaperi, 01 34 '54"S, $61^{\circ} 28^{\prime} 48^{\prime \prime} \mathrm{W}, \mathrm{MZUSP} 55804$ (7, CP 37,0 - 50,9mm); Pará: rio

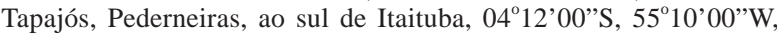
MZUSP 34710 (CP $31,7 \mathrm{~mm}$ ); rio Tapajós, entre Itaituba e São Luis, $04^{\circ} 27^{\prime} 00$ "S, 56 15 '00"W, MZUSP 34717 (4, CP 40,2 $58,8 \mathrm{~mm})$; rio Trombetas, $2 \mathrm{Km}$ abaixo do lago Aracuazinho, MZUSP 56559 (32, CP 33,5 - 51,0mm; 2 CP 46,2 e $50,7 \mathrm{~mm}$ d\&c); mesma localidade, MZUSP 56552 (5, CP 41,9 - 47,6mm).

Diagnose. Roeboides oligistos difere da maioria das espécies do grupo-affinis pelo reduzido número de raios ramificados da nadadeira anal, 38 a 44 (média=40,8), versus 40 a 56 (média=49,6). Somente em relação a $R$. biserialis, $R$. oligistos difere pelo elevado número de escamas perfuradas na linha lateral, 63 a 72 versus 56 a 60 e por possuir uma única série de dentes no dentário versus duas séries. De $R$. descalvadensis e $R$. sazimai, que apresentam sobreposição no número de raios ramificados da nadadeira anal, $R$. oligistos difere também pela ausência das manchas umeral e caudal e por apresentar, respectivamente, corpo mais baixo, altura maior no $\mathrm{CP}$ de 29,4 a $38,7 \%(m=34,2 \%)$, versus 34,3 a $45,4(m=38,9 \%)$. De $R$. affinis, que pode apresentar 42, 43 ou 44 raios da anal, $R$. oligistos difere pelo reduzido número de escamas da linha lateral, 63 a 72, versus 69 a 87 escamas.

Distribuição. Afluentes do médio e baixo rio Amazonas.

\section{Roeboides sazimai sp. nov. (Fig. 18A)}

Material examinado. Holótipo. BRASIL, Maranhão: rio Pindaré, Santa Inês, 339'36”'S, 4527'59”'W, 24 jul 1998, R. Reis, J.P. Silva, E. Pereira \& J. Montoya, MCP 38542 (CP 57,6mm).
Parátipos. BRASIL, Maranhão: igarapé do Pinto, Timon, 05³'37'S, 42 53'37'W, 26.VII.1998, R. Reis et al., MCP 22541

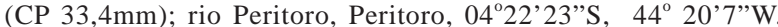
R. Reis et. al., MCP 22542 (CP 31,5mm); rio Pindaré, Santa

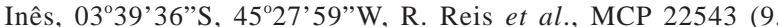
CP 45,8 - 56,2mm; 2 CP 44,6 e 56,5mm d\&c); lago do Viana, 8.V.1984, B.V. Moura, MZUSP 38723 (1, CP 77,0 mm); igarapé do Engenho, 4.IV.1984, B.V. Moura, MZUSP 38724 (2, CP 69,4 - 73,3mm); Piauí: riacho Fundo, Bananeiras, Teresina, $05^{\circ} 28^{\prime} 8^{\prime \prime} \mathrm{S}$, 42 ${ }^{\circ} 57^{\prime} 35^{\prime}$ W, 26.VII.1998, R. Reis et al., MCP 22540 (CP $44,5 \mathrm{~mm})$; rio Parnaíba, sob a ponte da $\mathrm{Br} 230$. Floriano, 06 48'30"S, 42 57'31'W, 07.IV.2005, William Severi et al., MCP 38005 (CP 54,2mm); rio Parnaíba, Uruçui, 07¹4'11"S, 443'35"W, 01.IV.2005, William Severi et al., MCP 38006 (CP 68,9mm); região alagada entre os rios Parnaíba e Balsas, Uruçui, 07 14'13"S, 4434'17'W, 01.IV.2005, William Severi et al., MCP 38007 (4, CP 69,9 - 71,8mm); rio Canindé, sob a ponte da BR343, Amarante, $06^{\circ} 17^{\prime} 41^{\prime \prime S}, 42^{\circ} 48^{\prime} 49^{\prime \prime} \mathrm{W}, 08$.IV.2005, William Severi et al., MCP 38008 (CP 49,5mm); mangue próximo ao centro de Parnaíba, VIII.1968, T. Roberts, MCZ 46786 (CP $35,6 \mathrm{~mm}$ ); rio Parnaíba, Barra do Longa, próximo a Buriti dos Lopes, $03^{\circ} 11$ 's, 41 ${ }^{\circ} 50^{\prime} \mathrm{W}, 2$ 27.VIII.1968, T. Roberts, MCZ 46788 (9, CP 33,3 - 83,6mm); rio Sambito, sistema do rio Parnaíba, São Félix, $05^{\circ} 56^{\prime} 00^{\prime \prime}$, $042^{\circ} 04^{\prime} 00^{\prime \prime} \mathrm{W}, 25 . \mathrm{I} .1982$, B.V. Moura, MZUSP $37884(\mathrm{CP} 62,1 \mathrm{~mm})$

Diagnose. Distingue-se de $R$. affinis pelo reduzido número de escamas da linha lateral, 64 a 70, versus 69 a 87; de $R$. numerosus e $R$. xenodon difere por apresentar 10 a 11 rastros no ramo inferior do primeiro arco branquial, versus 12 a 14 na primeira espécie e 7 a 8 na segunda espécie; de $R$. oligistos, pelo elevado número de raios ramificados da nadadeira anal, 42 a $48(\mathrm{~m}=45,1)$, versus 38 a $44(\mathrm{~m}=40,8)$; de $R$. biserialis difere por apresentar uma série de dentes no dentário versus duas. De Roeboides descalvadensis, que possui valores das contagens semelhantes, $R$. sazimai difere mais notadamente na forma geral do corpo, quando comparados exemplares de mesmo tamanho e acima de 60,0 $\mathrm{mm} \mathrm{CP}$ : focinho com perfil reto e comparativamente mais longo, $27,6 \%$ a $29,4 \%$ do comprimento da cabeça $(n=9, m=28,4 \%)$ e com corpo mais baixo, $34,8 \%$ a $39,2 \%$ do $\mathrm{CP}(\mathrm{n}=9, \mathrm{~m}=37,5 \%)$ (Fig. 14$)$, versus, focinho curto com perfil usualmente convexo, $25,5 \%$ a $28,0 \%(n=5, m=26,6 \%)$ do comprimento da cabeça e com corpo mais alto, $38,1 \%$ a $43,3 \%$ do $\mathrm{CP}(\mathrm{n}=5$, $\mathrm{m}=40,2 \%$ ). Na Análise de Componentes Principais os dois valores mais significativos que influenciaram no Componente II ( $3,12 \%$ da variância) para diferenciar essas duas espécies foram, o comprimento do focinho e a altura do corpo (Fig. 15, Tab. IV).

Descrição. Dados morfométricos na Tabela VI. Corpo alto. Perfil dorsal elevado a partir da base do processo supra-occipital até a origem da nadadeira dorsal, leve declive ao longo da base desta nadadeira, continuando-se reto até o pedúnculo caudal. Perfil ventral convexo até a origem na nadadeira anal, reto a partir daí até o pedúnculo caudal. Boca subterminal.

Focinho com perfil superior reto, ultrapassando a maxila inferior. Maxilar longo, extremidade posterior atingindo a vertical que passa pelo meio do olho ou levemente além, com sete a 14 dentes, os dois ou três primeiros, cônicos, seguidos, nos adultos, de um ou dois dentes mamiliformes, desenvolvidos, deslocados para a superfície externa do osso; os restantes mamiliformes, ou cônicos de base larga, localizados na borda do osso. 
Pré-maxilar com três dentes mamiliformes externos sem cúspides: um, anterior, desenvolvido, e dirigido para frente (corresponde ao dente D1 em LUCENA, 1998), outro localizado no ramo lateral e dirigido para fora (corresponde ao dente D2 em LuCENA, 1998), e o terceiro, acima do dente D2, dirigido para frente e para fora (correspondente ao dente D3 em LuCENA, 1998); D2 e D3 menores que o D1. Mais internamente, os dentes não possuem arranjo ou número definidos, diferindo, inclusive, de um prémaxilar para outro; na disposição mais constante ocorre uma fileira com quatro a seis dentes mamiliformes, desalinhados, que acompanha a borda interna do prémaxilar, o terceiro, ou quarto dente, mais desenvolvido e dirigido para frente; a seguir há dois dentes mamiliformes, posicionados próximos a junção entre os dois prémaxilares, segue-se um hiato e, na porção final do ramo lateral do pré-maxilar, uma fileira de quatro a seis dentes cônicos pequenos. Dentário com dois dentes mamiliformes externos sem cúspides, um anterior, dirigido para frente (correspondente ao dente D4 em LuCENA, 1998) e outro em posição lateral, e num plano mais inferior em relação ao D4, dirigido para fora (corresponde ao dente D5 em LuCENA, 1998); margem do dentário com um dente sinfiseal mamiliforme, grande, seguido de cinco a sete dentes cônicos ou mamiliformes pequenos e um mamiliforme grande, geralmente dirigido para fora, seguido por uma série de seis a 13 pequenos dentes cônicos de base larga. Todos os dentes sem cúspides. Rastros branquiais, cinco a oito [sete] no ramo superior $(n=34$, média=6,8), 10 a 11 [11] no inferior ( $\mathrm{n}=34$, média=10,8).

Nadadeira dorsal, i+9 raios, sua origem na vertical que passa levemente atrás da origem da nadadeira anal. Nadadeira peitoral, i+11 a 13 [13] raios ( $\mathrm{n}=34$, média=12,1), seu raio mais longo alcançando ou não a origem da nadadeira anal. Nadadeira ventral $i+7$ raios, seu raio mais longo ultrapassando a origem da nadadeira anal; machos com um gancho ósseo por segmento presente na metade superior da borda interna do primeiro ao quinto raio ramificado. Nadadeira anal, iv-v+42 a 48 [45] raios ( $n=33$, média $=45,1$ ); machos com um ou, mais raramente, dois ganchos ósseos por segmento presentes na borda interna do último raio não ramificado até, no máximo, o $10^{\circ}$ raio ramificado. Nadadeira caudal furcada com $\mathrm{i}+17+\mathrm{i}$ raios principais. Escamas da linha lateral, 64 a 70 [65] $(n=30$, média=67,3); escamas abaixo da linha lateral, 12 a 16 [14] $(\mathrm{n}=33$, média $=13,2)$; escamas acima da linha lateral, 13 a 17 [17] $(n=25$, média=14,7); escamas ao redor do pedúnculo caudal, 18 a 21 [20] ( $\mathrm{n}=19$, média=19,4). Trinta e sete vértebras totais, sendo 15 pré-caudais e 22 caudais em um exemplar d\&c.

Coloração em álcool. Corpo claro, alguns exemplares com uma estreita linha escura longitudinal, desde a região imediatamente posterior ao pseudotímpano até o final do pedúnculo caudal. Sobre esta linha pode ocorrer uma faixa prateada. Margem distal do focinho escurecida; margem distal da maxila inferior escurecida em alguns exemplares. Manchas umeral, quando presente, pequena, arredondada e usualmente, reduzida a poucos cromatóforos, localizada na região póstero-superior do pseudotímpano; mancha caudal, quando presente, grande e conspícua sobre o pedúnculo caudal e base dos raios medianos da nadadeira caudal; algumas vezes reduzida a poucos cromatóforos. Nadadeiras hialinas.

Etimologia. O nome especifico, sazimai, em homenagem a Ivan Sazima, pela sua valiosa contribuição ao conhecimento do hábito lepidofágico em Roeboides e à ictiofauna brasileira em geral.

Distribuição. Sistemas dos rios Parnaíba e PindaréMearim, nordeste do Brasil (Fig. 13).

Tabela VI. Dados morfométricos de R. sazimai, sp. nov., e Roeboides xenodon (m, média; n, número de exemplares, incluindo o holótipo; SD, desvio padrão; A, holótipo de R. sazimai, MCP 38542; B, lectótipo de R. francisci, NWM 56896).

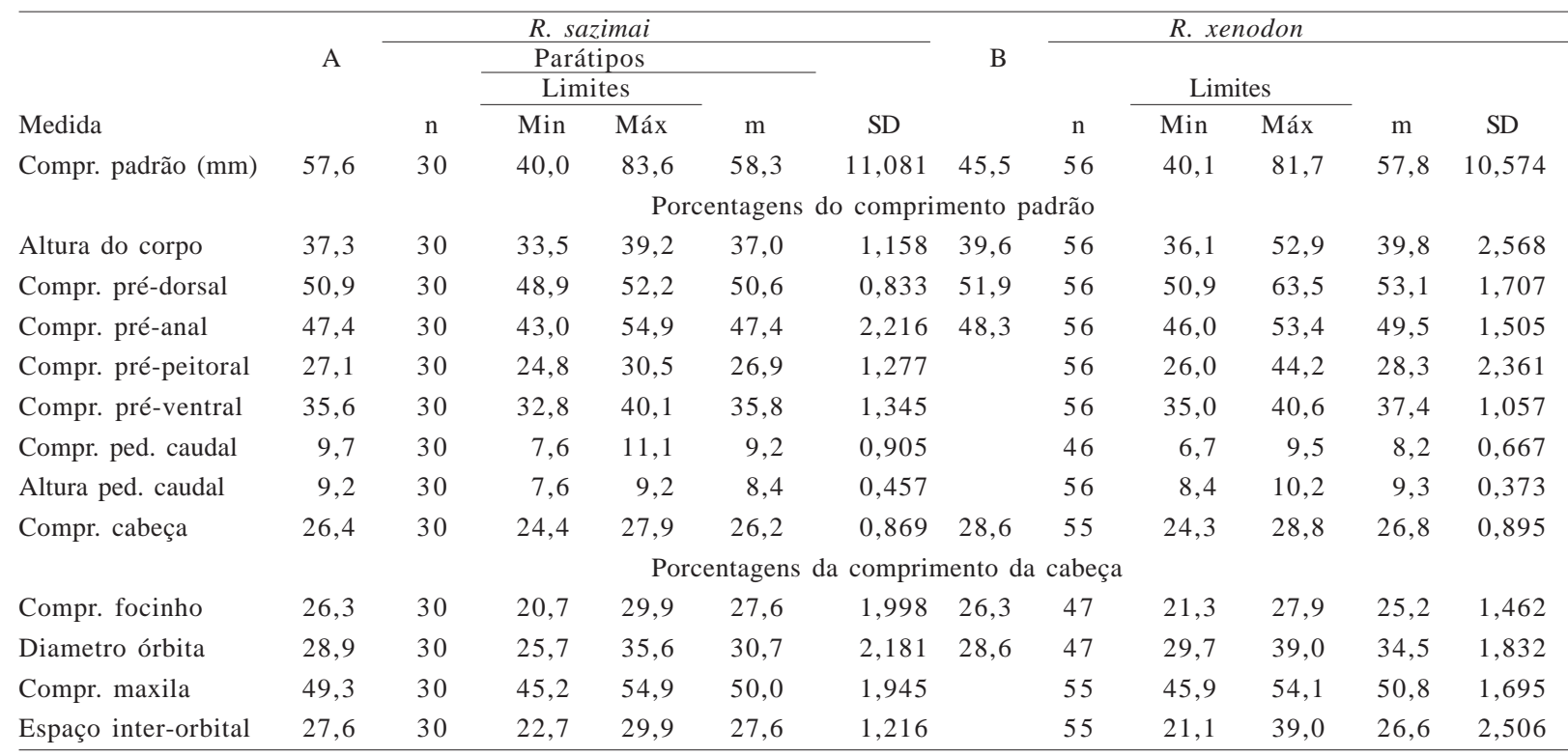




\section{Roeboides xenodon Reinhardt, 1851}

(Fig. 18B)

Epicyrtus xenodon RIENHARDT (1851: 37) (Localidade-tipo: ribeirão do Mato, lagoa Santa, rio das Velhas, bacia do rio São Francisco). Cynopotamus (Roeboides) xenodon LÜTKEN (2001:116) (nomenclatura).

Raeboides (sic) francisci STEINDACHNER (1908:192). (Localidadetipo: rio Preto, afluente do rio Grande, sistema do rio São Francisco; restringida aqui pela designação de lectótipo).

Material examinado. BRASIL, Minas Gerais: sistema do rio São Francisco, MCP 13988 (CP 59,9mm); barragem de Três Marias, MCP 14021 (2, CP 49,0 - 59,4mm); mesma procedência, MCP 14028 (3, CP 32,4 - 37,3mm); mesma procedência, MCP 14030 (12, CP 29,0 - 44,3mm); arroio saindo da barragem na fazenda J.B. próximo à BR040, 15 ${ }^{\circ} 9^{\prime} 36^{\prime \prime} \mathrm{S}, 44^{\circ} 40$ '52"W, MCP17044 (3, CP 51,4 - 55,5mm); rio Verde, estrada Montes Claros-Janaúba, 16³9'01'S, 4342'49”W, MCP 17064 (4, CP 43,8 - 58,2 mm). Bahia: rio da Olaria, $30 \mathrm{Km}$ de Malhada, 14 15'34"S, 4317'27'W, MCP 16920 (50, CP 25,5 - 46,0mm); riacho Santana a $31 \mathrm{Km}$ ao sul de Bom Jesus da Lapa, 1331'13'S, $43^{\circ} 21$ '28"W, MCP 16921 (40, CP 38,3 - 81,7mm; 3 CP 51,6, 56,0 e $59,8 \mathrm{~mm}$ d\&c); rio Pau da Colher na estrada GuanambiMutas, 14 ${ }^{\circ} 12^{\prime} 48^{\prime \prime} \mathrm{S}, 42^{\circ} 49^{\prime} 30^{\prime \prime} \mathrm{W}$, MCP 17056 (CP 23,7mm).

Diagnose. Difere de todas as espécies do grupoaffinis por apresentar a região ântero-inferior do cleitro fracamente diferenciada do restante da osso com uma ponta pequena dirigida para frente e por ter 7 a 8 rastros no ramo inferior do primeiro arco branquial versus mesma região do cleitro, arredondada, não diferenciada do restante do osso, e com 9 a 14 rastros nas demais espécies. Embora $R$. affinis possa apresentar, raramente, 8 rastros no ramo inferior do primeiro arco branquial, especialmente na população do sistema Tocantins-Araguaia, o número de escamas da linha lateral distingue ambas as espécies, 69 a 87 versus 55 a $69 \mathrm{em} R$. xenodon. De $R$. biserialis, que possui número semelhante de rastros branquais e de escamas perfuradas da linha lateral, $R$. xenodon difere por possui uma única fileira de dentes no dentário versus duas fileiras. Além disso, possui os dentes externos no dentário, D4 e D5 e a mancha umeral é verticalmente alongada em $R$. xendon enquanto $R$. biserialis não apresenta os dentes D4 e D5 e a mancha umeral é arredondada.

Descrição. Dados morfométricos na Tabela VI. Corpo alto. Perfil dorsal elevado a partir da base do processo supra-occipital até a origem da nadadeira dorsal, leve declive ao longo da base desta nadadeira, continuando-se reto até o pedúnculo caudal. Perfil ventral convexo até a origem na nadadeira anal, reto a partir daí até o pedúnculo caudal. Boca subterminal.

Focinho com perfil superior convexo, estendendose pouco além da maxila inferior. Maxilar longo, extremidade posterior podendo atingir o meio do olho ou entre o meio do olho e a margem posterior da órbita, com seis a 11 dentes, os três ou quatro primeiros, cônicos, seguidos, nos adultos, de dois ou três dentes mamiliformes, desenvolvidos, deslocados para a superfície externa do osso; os restantes mamiliformes, ou cônicos de base larga, localizados na borda do osso. Pré-maxilar com três dentes mamiliformes externos sem cúspides: um, anterior, desenvolvido, e dirigido para frente (corresponde ao dente D1 em LuCENA, 1998), outro localizado no ramo lateral e dirigido para fora (corresponde ao dente D2 em LUCENA,
1998), e o terceiro, acima do dente D2, dirigido para frente e para fora (correspondente ao dente D3 em LuCENA, 1998); D2 e D3 menores que o D1; dente D3 podendo faltar. Mais internamente, os dentes não possuem arranjo ou número definidos, diferindo, inclusive, de um prémaxilar para outro; na disposição mais constante ocorre uma fileira com quatro a cinco dentes mamiliformes, desalinhados, que acompanha a borda interna do prémaxilar, o terceiro, ou quarto dente, mais desenvolvido e dirigido para frente; a seguir há dois dentes mamiliformes, posicionados próximos a junção entre os dois prémaxilares, segue-se um hiato e, na porção final do ramo lateral do pré-maxilar, uma fileira de quatro a cinco dentes cônicos pequenos. Dentário com dois dentes mamiliformes externos sem cúspides, um anterior dirigido para frente (correspondente ao dente D4 em LuCENA, 1998) e outro em posição lateral, e num plano mais inferior em relação ao D4, dirigido para fora (corresponde ao dente D5 em LuCENA, 1998); margem do dentário com um dente sinfiseano mamiliforme, grande, seguido de cinco a seis dentes cônicos ou mamiliformes pequenos e um mamiliforme grande, geralmente dirigido para fora, seguido por uma série de nove a 14 pequenos dentes cônicos de base larga. Todos os dentes sem cúspides. Rastros branquiais, três a cinco no ramo superior $(n=55$, média $=4,1)$, sete a oito no inferior $(\mathrm{n}=56$, média $=7,6$ ).

Nadadeira dorsal i+9 raios, sua origem na vertical que passa levemente atrás da origem da nadadeira anal. Nadadeira peitoral, $\mathrm{i}+11$ a 13 raios $(\mathrm{n}=56$, média $=11,9)$, seu raio mais longo alcançando ou não a origem da nadadeira anal. Exemplares até $26,0 \mathrm{~mm}$ CP com nadadeira peitoral na forma larval. Nadadeira ventral i+7 raios, seu raio mais longo ultrapassando a origem da nadadeira anal; machos com um ou dois ganchos ósseos, por segmento, presentes na metade superior da borda interna do primeiro ao quinto raio ramificado. Nadadeira anal iv-v+41 a 47 raios $(n=48$, média $=43,4)$; machos com um ou, mais
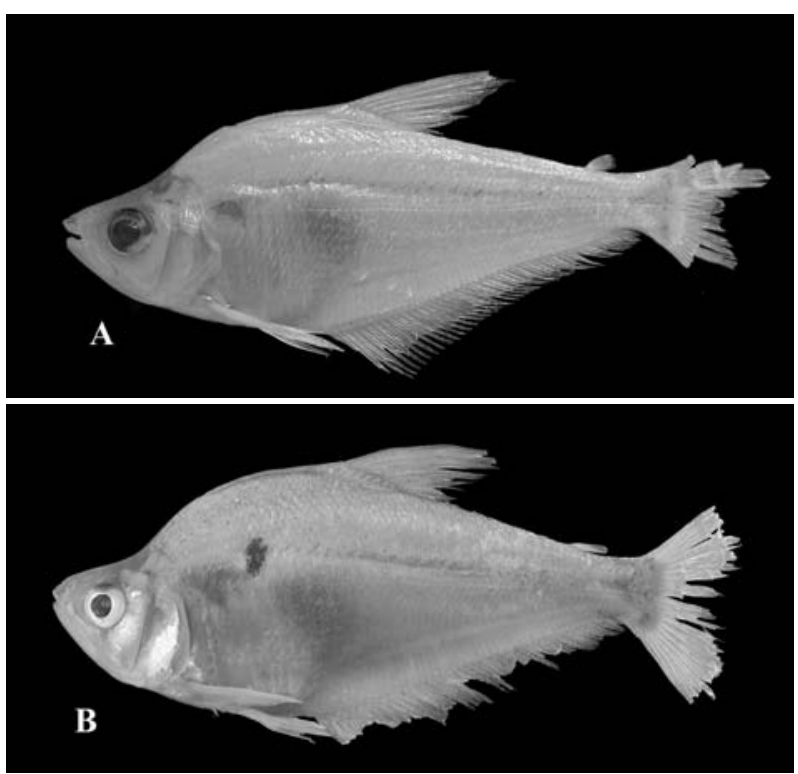

Fig. 18. A, Roeboides sazimai sp. nov., rio Pindaré, Maranhão, MCP 38542, holótipo, CP 57,6mm. B, Roeboides xenodon Reinhardt, 1851, riacho Santana, Bahia, MCP 16921, CP $78,7 \mathrm{~mm}$ 
raramente, dois ganchos ósseos por segmento, presentes na borda interna do último raio não ramificado até, no máximo, o $15^{\circ}$ raio ramificado. Nadadeira caudal furcada com $\mathrm{i}+17+\mathrm{i}$ raios principais. Escamas da linha lateral, $55 \mathrm{a}$ 69 ( $n=54$, média=62,7); escamas abaixo da linha lateral, 10 a $13(n=56$, média=11,7); escamas acima da linha lateral, 10 a 15 (n=47, média=13,1); escamas ao redor do pedúnculo caudal, 17 a 20 (n=41, média=18,1). Trinta e oito vértebras, sendo 15 pré-caudais e 21 ou 23 caudais (dois exemplares $\mathrm{d} \& \mathrm{c})$.

Coloração em álcool. Corpo claro, algumas vezes com uma estreita faixa escura longitudinal, que pode estar interrompida em vários segmentos, desde a região imediatamente posterior ao pseudotímpano até o final do pedúnculo caudal; essa faixa é normalmente acompanhada por uma série de manchas em forma de < . Margem distal do focinho escurecida; margem distal da maxila inferior escurecida em alguns exemplares. Mancha umeral conspícua, verticalmente alongada mas não ultrapassando a linha lateral, localizada a cerca de 2 a 3 escamas da região póstero-superior do pseudotímpano; mancha caudal, grande e conspícua larga na base dos raios da nadadeira caudal e afilando-se para frente. Nadadeiras hialinas.

\section{Distribuição. Sistema do rio São Francisco (Fig. 13).}

Comentários. Epycirtus xenodon, ReInHARDT (1851), foi descrita a partir de exemplares do ribeirão do Mato, lagoa Santa, afluente do rio das Velhas, Minas Gerais. Todos os exemplares depositados no Museu de Zoologia de Copenhagen estão em bom estado (J. Nielsen in litteris). Desta forma, foi selecionado o maior exemplar, ZMUC P281118 (antigo ZMUC 203), CP 94,0mm, como lectótipo. Os demais lotes, ZMUC P281119, ZMUC P2281120, ZMUC P281121 e, conforme Eschmeyer (2205), ZMB 9193 e MNHN 9885 são considerados paralectótipos.

Raeboides (sic) francisci, STEINDACHNER (1908) foi descrita a partir de numerosos exemplares coletados durante uma expedição ao nordeste do Brasil (VANZOLINI, 1992) em lagoas na cidade de Barra, foz do rio Grande, e no rio Preto, afluente do rio Grande, ambas localidades no médio rio São Francisco, Bahia. Foi selecionado como lectótipo o maior exemplar do lote NMW 56896, (CP $45,5 \mathrm{~mm}$ ), procedente do rio Preto. Em consequência os demais 12 exemplares do mesmo lote, NWM 56891, NWM 56892 (71exs.), NWM 56893 (19exs.), NWM 56894 (25exs.), NWM 56895 (7exs.), NWM 56897 (2exs.), NWM 56920 NWM 56921 (16exs.) e NWM 56922 (9exs.) ficam aqui designados paralectótipos. Na cópia das páginas do livro de registros enviados por B. Herzig (à época curadora da coleção), há nos lotes NMW 56898 (56exs.), 56900 (4exs.) e 56899 o sinal "?”, ao lado da palavra "Syntypus". Em vista disso, tais lotes não foram considerados paralectótipos.

Agradecimentos. Pelo empréstimo de material, envio de fotos ou informações (inlcuindo medidas e/ou contagens) sobre exemplares aos seus cuidados: J. Lundberg e Mark Sabaj (ANSP); James Maclaine (BMNH), Fernando Carvajal Vallejos (UMSS); Jose Ivan Mojica (ICN-MHN); Mark Sabaj (à època no INHS); Lucia Py-Daniel (INPA); Wellendorf Helmut (NMW), Roman-
Valencia (MBUC-V); Karsten Hartel (MCZ); Dario Mandelburger (MNHNP); Hernán Ortega (MUSM); Osvaldo Oyakawa e José L. Figueiredo (MZUSP), Sven Kullander e Erik Ahlander (NRM); James Albert (à epoca na UF) e William Crampton (UF); Douglas Nelson (UMMZ); Paulo F. Lucinda (UNT); Susan Jewet (à época no USNM); E. J. Crossman e Erling Holm (ROM); Isaäc Isbrüecker (ZMA), Jørge Nielsen (ZMUC). À Dra Lilian Casatti, IBILCE UNESP, pela doação de exemplares de $R$. paranensis do rio Paranapanema. As fotos foram tiradas por Vinicus Bertaco (MCP). Ao Dr. Ivan Sazima, Universidade de Campinas, por compartilhar suas idéias sobre aspectos comportamentais e taxonômicos do grupo-affinis. À Alexandre Charkanski (MCP) pela elaboração e edição da Figura 12. A coordenadora do Centro de Microscopia e Microanálise (CEMM) da PUCRS pelo uso das instalações. O projeto de revisão taxônomica e filogenia de Roeboides, do qual esse trabalho faz parte, foi beneficiado com auxílios do CNPq (Procs. 40.0051-94.0 e 475253/2004-3) e FAPERGS (Proc. 93/2811.3). Os consultores da revista, Flávio Lima e Ricardo Benine, contribuiram para melhorar o trabalho com suas pertinentes, e apropriadas, sugestões.

\section{REFERÊNCIAS BIBLIOGRÁFICAS}

Bookstein, F. L.; Chernoff, B.; Elder, R.; Humphries, J.; Smith, G. \& Strauss, R. 1985. Morphometrics in Evolutionary Biology. Philadelphia, Academy of Natural Sciences Press. 277p. (Special Publication).

Boulenger, G. A. 1895. Abstract of a report on a large collection of fishes formed by Dr. C. Ternetz in Matto Grosso and Paraguay, with descriptions of new species. Proceedings Zoological Society 1895(3):523-529.

1896. III. On a collection of fishes from the Rio Paraguay. Transactions Zoology Society 14(2):25-39.

Calcagnotto, D.; Schaefer, S. \& DeSalle, R. 2005. Relationships among characiform fishes inferred from analysis of nuclear and mitochondrial gene sequences. Molecular Phylogenetics and Evolution 16(2005):135-153.

COPE, E. D. 1870. Contribution to the ichthyology of the Marañon. Proceedings American Philosophical Society 11:559-570.

Dingerkus, G. \& Uhler, L. 1977. Enzyme clearing alcian blue stained whole vertebrates for demostration of cartilage. Stain Technology 52:229-232.

Eigenmann, C. H. 1903. New genera of South American freshwater fishes, and new names for old genera. Smithsonian Miscellaneous Collections 45:144-148.

Eigenmann, C. H. 1912. The freshwater fishes of British Guiana, including a study of the ecological grouping of species, and the relation of the fauna of the plateau to that of the lowlands. Memoires Carnegie Museum 5(1):i-xxii + 1578, Plates 1-103.

Eigenmann, C. H \& Ogle, F. 1907. An annoted list of charcters fishes in the United States Museum and the Museum of Indiana University, with descriptions of new species. Proceedings United States National Museum, 23(1556): 1-86.

Fink, W. L. \& Weitzman, S. H. 1974. The so-called Cheirodontin fishes of Central America with descriptions of two new species (Pisces: Characidae). Smithsonian Contributions to Zoology 172:1-46.

Fowler, H. W. 1904. Note on the Characinidae. Proceedings Academy Natural Sciences 56:119.

Fowler, H. W. 1932. Zoological results of the Mato Grosso Expedition to Brazil in 1931. I. Fresh water fishes. Proceedings Academy Natural Sciences 84:343-377.

Garman, S. 1890. On the species of Cynopotamus. Bulletin Essex Institute 22(1-30):11-14.

Günther, A 1868. Descriptions of freswaters fishes from Surinam and Brazil. Proceedings Zoological Society 1868(2): 229-247.

Hardman, M.; Page, L. M.; Sabaj, M. H.; Armbruster, J. W. \& KnoufT, J. H. 2002. A comparasion of fihs surveys made in 1908 and 1998 of the Potaro, Essequibo, Demerara, and coastal river drainages of Guyana. Ichthyological Explorations Freshwaters 13(3):225-238.

Hahn, N. S.; Pavanelli, C. S. \& Okada, E. K. 2000. Dental 
development and ontogenetic diet shifts of Roeboides paranensis (Osteichthyes, Characinae) in pools of the upper Rio Paraná floodplain (State of Paraná, Brazil). Revista Brasileira de Biologia 60(1):93-99.

Hammer, Ø. \& Harper, D. A. T. 2003. Past version $0.87 \mathrm{~b}$. Disponível em: 〈http://folk.uio.no/ohammer/past〉. Acesso em: 05.07.2005.

Henn, A. W. 1928 List of types of fishes in the collection of the Carnegie Museum on September 1, 1928. Annales Carnegie Museum 9(4):51-99.

HiguchI, H. 1992. An updated list of ichthyological collecting stations of the Thayer Expedition to Brazil. Electronic version (1996). Disponível em: <http://www.mcz.harvard.edu/ Departments/Fish/thayer.htm>. Acesso em: 03.02.2005.

Ibarra, M. \& Stewart, D. J. 1987 Catalogue of type specimens of Recent fishes in Field Museum of Natural History. Fieldiana Zoology 35:1-112.

Lucena, C. A. S. de. 1988. Lista comentada das espécies do gênero Roeboides Günther, 1864 descritas para as bacias dos rios Amazonas, São Francisco e da Prata (Characiformes, Characidae, Characinae). Comunicações Museu Ciências Tecnologia PUCRS, Série Zoologia 1(3):29-47.

1998. Relações filogenéticas e definição do gênero Roeboides Günther (Ostariophysi: Characiformes: Characidae). Comunicações Museu Ciências Tecnologia PUCRS, Série Zoologia, 11:19-59.

. 2000a. Revisão taxonômica e filogenia das espécies transandinas do gênero Roeboides Günther (Teleostei: Ostariophysi: Characiformes). Comunicações Museu Ciências Tecnologia PUCRS, Série Zoologia, 13:3-63. 2000b. Duas novas espécies do gênero Roeboides Günther das bacias dos rios Orinoco e Amazonas (Teleostei, Characiformes, Characidae). Biociências 8(2):153-162.

2001 Uma nova espécie de Roeboides Günther da região superior da bacia Amazônica (Teleostei: Characiformes: Characidae). Biotemas 14(2):61-70.

2003. Revisão taxonômica e relações filogenéticas das especies de Roeboides grupo-microlepis. Iheringia, Série Zoologia, 93(3):283-308.
Lucena, C. A. S. \& Menezes, N. A. 2003. Subfamily Characinae In: Reis, R. E.; Kullander, S. O. \& Ferraris JR., C. J. eds. Check list of the freshwater fishes of South and Central America. Porto Alegre, Edipucrs. p.200-208.

Lütken, C. F. 2001. Peixes do Rio das Velhas: uma contribuição para a Ictiologia do Brasil. In: Alves, C. B. M. \& Pompeu, P. S. eds. Peixes do Rio das Velhas: passado e presente. Belo Horizonte, SEGRAC, cap. 2, p.23-164.

Novakowski, G.; Fugi, R. \& Hahn, N. S. 2004. Diet dental developmente of three species of Roeboides (Characiformes: Characidae). Neotropical Ichthyology 2(3):137-162.

Peterson, C. C. \& McIntyre, P. 1998. Ontogenetic diet shifts in Roeboides affinis with morphological comparasions. Environmental Biology of Fishes 53:105-110.

Peterson, C. C. \& Winemiller, O. 1997. Ontogenetic diet shifts in Roeboides dayi, a Neotropical characid. Environmental Biology of Fishes 49:111-118.

Pignalberi, C. T. 1975. Una nueva especie del género Roeboides Günther del río Paraná: Roeboides paranensis sp. nov. (Pisces, Characidae). Physis 34(89):151-155.

Reinhardt, J. T. 1851 Nye sydamerikanske Ferskvandsfiske. Videnskabelige Meddelelser naturhistoriske Forening 1849(3-5):29-57.

SAZIMA, I. 1984. Scale-eating in characoids and other fishes. In: Zeret, J. M. ed. Evolutionary ecology of Neotropical freshwater fishes. The Netherlands, The Hague. p.9-23

Sazima, I. \& Machado, F. A. 1982 Hábitos e comportamento de Roeboides prognathus (Osteichthyes, Characoidei). Boletim Zoologia Universidade São Paulo 7:37-56.

Steindachner, F. 1908. Über zwei neue Fischarten aus dem Stromgebiete des Rio San Francisco. Anzeiger der Akademie der Wissenshaften 45(13): 191-194

VAnzolini, P. E. 1992. Itinerary of the Austrian Expedition to Northeastern Brazil. Anais da Academia Brasileira de Ciências 64(4):397-405.

Weitzman, S. \& Malabarba, L. R. 1999. Systematics of Spintherobolus (Teleostei: Characidae: Cheirodontinae) from eastern Brazil. Ichthyological Explorations Freshwaters 10(1):1-43. 